\title{
MEJORAMIENTO GENÉTICO Y ADAPTACIÓN DE PAPAS DE CALIDAD INDUSTRIAL A LAS ZONAS AGROECOLÓGICAS ARIDAS Y SALINAS DE LA COSTA PERUANA
}

\author{
René Chávez Alfaro ${ }^{1}$, Mahesh Upadhya ${ }^{2}$, Rolando Cabello ${ }^{2}$, \\ Humberto Mendoza ${ }^{2}$, Jorge Espinoza ${ }^{2}$, Arie Wijntje ${ }^{3}$, \\ John Scoffield, Walter Amoros ${ }^{2}$, Porfirio Siles' .
}

\author{
RES UMEN
}

\begin{abstract}
El descubrimiento de la variabilidad genética para resistencia a salinidad y sequía en el germoplasma hexaploide nativo y cultivares de camote $(2 n=6 x=90=B B B B B B)$ y en poblaciones clonales autotetraploides de papa $(2 n=4 x=48=A A A A)$, a principios de 1985 catalizó el inicio de una investigación aplicada sobre respuestas fenotípicas de las plantas tuberíferas a los estreses abióticos más comunes de las zonas áridas y salinas de potencial agrícola de la costa Peruana. Se estableció el mismo año el proyecto de investigación colaborativa de "Mejoramiento genético de papa y camote para zonas áridas y salinas" entre la Facultad de Ciencias Agricolas de la Universidad Nacional de Tacna y el Departamento de Genética y Mejoramiento del Centro Internacional de la Papa. En una etapa más avanzada del proyecto participó el Departamento de Fisiología del CIP y los expertos agrícolas de la Comunidad Económica Europea-INADE, Convenio ALA/93, Majes, Arequipa.
\end{abstract}

Dentro de la estrategia genética y logística del proyecto se diseñó un programa de cruzamientos y selecciones recurrentes para generar familias híbridas promisorias y clones elites, así como progenitores con buena habilidad combinatoria adaptados a las condiciones agroecológicas áridas y salinas de potencial agrícola de la costa Peruana. El germoplasma mejorado, una vez introducido al sistema de cultivo in vitro de tejidos para su limpieza de virus y micropropagación masal y luego liberado bajo un programa sostenible de semilla libre de patógenos, sería utilizado por los agricultores de ésta zona agroecológica para consumo directo y en la producción y abastecimiento permanente de materia prima para la agroindustria.

Se ha logrado una amplia ganancia genética y un avance de selección, materializado mayormente por un caudal de clones avanzados, familias híbridas de semilla botánica (TPS) y variedades superiores, adaptadas a las condiciones climáticas y edáficas de los suelos costeros de potencial agrícola, así como una marcada resistencia de campo al nemátodo del nudo de la raíz Meloidogyne incógnita, importante plaga de la papa y el camote en la costa y una resistencia de campo a los virus PVX y PVY, como parte de un manejo ecológico integrado del control de plagas y enfermedades en la costa árida.

Palabras claves: ganacia genética, resistencia a estreses abióticos, tolerancia al calor, precocidad, fotoperiodo, calidad industrial.

Facultad de Ciencias Agrícolas, Universidad Nacional Jorge Basadre Grohmann. Tacna - Perú.

Departamento de Fisiologia y Genética, Centro Internacional de la Papa. Lima-Perú.

Comunidad Económica Europea - INADE, Convenio ALA/93, Majes - Arequipa. 


\section{A B S T R A C T}

The discovery of the genetic variability for resistance to salinity and drought in the native hexaploidal germoplasma and yam cultivares $(2 n=6 x=90=B B B B B B)$ and in autotetraploidal populations of potatoes $(2 n=4 x=48=A A A A)$, at the beginning of 1985 catalized the beginning of an investigation based upon the phenotopic responses of tubiferous plants to the most common abiotic stresses in arid and saline areas of agricultural potential on the Peruvian coast. The same year, the project of investigation of "genetic Improvement of potato and yam for arid and saline areas" was set up, acollaboration between the Faculty of Agricultural Sciences of the National University of Tacna and the Department of Genetics and Improvement at the International Potato Center. In a more advanced stage of the project the Department of Physiology of the CIP, and the agricultural experts of the European Economic Community - INADE, [Agreement ALA/93, Majes, Arequipa] participated.

Within the genetic strategy and logistics of the project a program of crossing and recurrent selections was designed, to generate promissory hybrid families and elite clones, as well as progenitors with good combinatory ability adapted to the arid and saline agroecologica conditions of agricultural potential of the Peruvian coast. The improved germoplasma, once introduced to the in vitro cultivation system of fabrics for virus cleaning and micropropagation masal, and then liberated under a sustainable program of seed free patogens, would be used by the farmers of this agroecologica area for direct consumption and in the production and permanent supply of primary materials for agroindustry.

A wide genetic gain and a selection advance has been achieved, materialized mostly by a flow of advanced clones, hybrid families of botanical seeds (TPS) and superior varieties, adapted to the climatic and son conditions of the coastal floors of agricultural potential, as well as a marked field resistance to the "nemátodo" of the knot of the root Meloidogyne incógnita, as important pest of the potato and the yam on the coast, and a field resistance to the viruses PVX and PVY, as part of an integrated ecological handling of the control of pests and illnesses on the arid coast.

Key words: genetic gain, resistence to abiotic stresses, tolerance to heat, precocity, photoperiod, industrial quality.

\section{INTRODUCCIÓN}

Dentro de la clasificación general de las zonas agroecológicas del mundo, la Zona Arida es el ambiente ecológico más extenso en el cinturón tropical del tercer mundo y es la que presenta los mayores estreses abióticos a las plantas cultivadas, principalmente sequía, salinidad, toxicidad de boro y calor. Estos estreses no solo reducen los rendimientos de las plantas cultivadas, sino también limitan la extensión y explotación racional de nuevas variedades comerciales susceptibles. El manejo integrado de los estreses abióticos en las zonas áridas de potencial agrícola, siempre ha sido fuertemente orientado al manejo altamente tecnificado del agua y suelo, así como la selección del cultivo en la estación óptima del año. Sin embargo, recién desde la última década se ha venido dando mayor importancia a otro componente del manejo integrado de zonas áridas, el potencial genético de las especies cultivadas para tolerar los estreses abióticos como producto de una superioridad heredada o una combinación favorable de genes bajo la mano del fitomejorador moderno.
El potencial agrícola de la zona agroecológica árida y salina de Sud América es inmenso, abarca prácticamente todo el territorio costanero del Perú y Norte de Chile, con una extensión aproximada de 4000 kilómetros de largo y un promedio de 80 kilómetros de ancho. Dentro de esta zona se encuentran los grandes desiertos de Sechura y Atacama. La naturaleza como producto de la evolución darwiniana durante miles o millones de años, ha generado especies vegetales con alta frecuencia de genes de resistencia a la sequía, salinidad y toxicidad de boro, tal es el caso del Tamarugo (Prosopis tamarugo) del desierto de Atacama y del tomate Lycopersicon peruvianum L. Chilensi del desierto sur peruano. En este sentido, el avance de los cultivos hacia zonas marginales mayormente áridas y salinas, ha hecho que se preste una especial atención a la investigación sobre respuestas fenotípicas de las plantas a la salinidad y al estrés de la sequía. Para el caso particular de la papa, los estreses abióticos edáficos y las altas temperaturas de verano, limitan 
la producción sostenida del cultivo, así como el suministro permanente de materia prima fresca para la agroindustria.

Durante trece años de intensiva y continua experimentación genética en papa, tanto en campos experimentales como en chacra de agricultores se ha generado más de 32000 clones y familias híbridas promisorias. De este material se seleccionaron 105 clones avanzados y 37 clones superiores muy precoces, adaptados a las condiciones áridas y salinas, y de buena calidad para la agroindustria. Los últimos experimentos ejecutados en el sur del Perú bajo condiciones de un clima cambiante por el fenómeno del Niño, con una alta temperatura durante todo el año, aún en la estación de invierno, y una continua y densa neblina en las zonas paperas de la costa sur causaron serios daños al cultivo de la papa. Miles de hectáreas de papa cultivadas con variedades comerciales de invierno se perdieron o presentaron muy bajos rendimientos debido al efecto estresante del calor ambiental y edáfico que afectó la normal tuberización de las plantas. La conducción de 16 experimentos de papa en el campo fue fuertemente afectada por el fenómeno climático de EI Niño en Tacna, Arequipa y Moquegua. Sin embargo, esto permitió evaluar e identificar preliminarmente la resistencia o la susceptibilidad de variedades, clones y familias híbridas a algunos estreses bióticos y abióticos muy raros en tiempos normales, tales como la Rancha de la Papa, la alta ocurrencia poblacional de Russeliana solanicola y la degeneración clonal por efecto de nuevas razas virulentas en la zona.

\section{LAZONA AGROECOLÓGICA ARIDA Y SALINA DE LA COSTA PERUANA: CARACTERÍSTICAS CLIMATICAS Y EDAFICAS}

La zona agroecológica árida y salina con potencial agricola de la costa peruana comprende un territorio con cerca de cinco millones de hectáreas. Sin embargo solo una pequeña fracción de este territorio es cultivado debido a los estreses abióticos mayormente edáficos frecuentes que afectan el rendimiento y la productividad de las plantas cultivadas. Sin embargo la alta temperatura reinante durante la primavera y el verano es también un factor fuertemente limitante para el cultivo de la papa, cuya tuberización es inhibida por el calor. Otro singular estrés abiótico climático podríamos considerar las diferencias de fotoperiodo durante el año, sobre todo a $17^{\circ}$ y $18^{\circ}$ latitud Sur. En el extremo sur del Perú (Tacna y Moquegua) hay una respuesta fenotípica efectiva de las plantas cultivadas a los diferentes fotoperiodos que marcadamente se aprecian durante las cuatro estaciones del año. Para una producción sostenida durante todo el año de un cultivo anual y precoz sería necesario tener disponible variedades insensibles al fotoperiodo. Sin embargo la variabilidad buscada se encuentra en baja frecuencia, su naturaleza genética es compleja y su gobierno es poligénico.

Los estreses abióticos edáficos son más determinantes en la producción sostenida de los cultivos. Uno de los mayores estreses es la salinidad de éstas zonas áridas, la sal dominante es el cloruro de sodio de origen marino, encontrándose en el suelo a niveles elevados que fluctúan entre 5 y $20 \mathrm{mmhs} / \mathrm{cm}$. y en una capa arable de $20 \mathrm{~cm}$ de profundidad. El otro estrés importante es la ocurrencia de boro en el suelo pero a niveles mayormente tóxicos, cuya fluctuación común va de 4 a 10 ppm. en una capa arable de 20 a $25 \mathrm{~cm}$. Los estudios edafológicos in situ y los análisis de más de 2000 muestras de suelo en laboratorio y numerosas calicatas indican la existencia de una gran variabilidad dinámica horizontal, vertical y temporal de la salinidad y del contenido de Boro en los diferentes estratos y horizontes edáficos. Los resultados de los análisis de los suelos desérticos vírgenes, han sido sorprendentes, se ha detectado una enorme variabilidad horizontal y vertical de la concentración de sales en los estratos edáficos. Las franjas horizontales de salinidad pueden variar de 10 a $120 \mathrm{mmhs}$ en pocos metros o kilómetros. La variabilidad vertical de los horizontes edáficos, es aun más conspicua, variando en algunos casos de 8 a 50 mmhs., a pocos centímetros o decímetros.

El contenido de boro en el suelo puede variar vertical u horizontalmente de 4 a $10 \mathrm{ppm}$. y excepcionalmente de 4 a $16 \mathrm{ppm}$. como ocurre en los valles de Sama, Locumba, Ite y Lluta. En general, los niveles de salinidad bajan gradualmente a medida que se incrementa el número de riegos. En muchos suelos áridos y franco arenosos el contenido de sales baja a su nivel inferior el día del riego, y va incrementándose día a día hasta el siguiente riego. Este cambio se hace aún más dinámico durante el verano que en el invierno, y más aún en los suelos arenosos y franco arenosos con poca capacidad de campo por el exceso de evaporación de agua del suelo, que arrastra las sales de los horizontes bajos hacia la superficie. Sin embargo, la variabilidad de la salinidad en el tiempo, se lleva a cabo mayormente en el fondo del surco y en los niveles friáticos de riego. El lomo del surco 


\section{HEM ROTECA CEMTRAL UNIBG}

(nivel no friático) permanece relativamente estable con niveles elevados de sal debido a la constante migración vertical de las sales de la parte húmeda a la parte seca. Se ha detectado en algunos suelos fuertemente salinos, que la conductividad puede variar entre el fondo y el lomo del surco de 5 a $50 \mathrm{mmh}$., tal es el caso de algunos suelos de La Yarada y Los Palos, ubicados todavía dentro del desierto de Atacama en el Departamento de Tacna.

El agua de origen subterráneo extraída de los pozos que se utiliza en algunos cultivos es ligeramente salina, con una concentración que fluctúa de 1 a $3 \mathrm{mmh} / \mathrm{cm}$., variando de acuerdo a su proximidad al mar. Al evaporarse el agua a riego, contribuye aunque en poca escala, a la salinización del suelo debido a la ausencia de drenajes. Por otra parte, el agua de riego de origen altoandino proveniente mayormente de las lagunas en el sur del Perú, contiene niveles moderados de boro que al evaporarse contribuye también al incremento del boro tóxico en el suelo cultivado, causando daños fisiológicos a las plantas cultivadas, como se observa en las hojas cloróticas de los cítricos y en la fuerte quemadura del borde de las hojas de plantas de palto, guayaba y lúcuma. Sin embargo en algunas regiones de la costa peruana, la presencia en el suelo de carbonato de calcio reduce los efectos perniciosos del boro a niveles tóxicos. En el cultivo de la papa el aporque arrastra las sales de la parte superior no freática de los surcos hacia la base de los tallos de la planta. Una vez irrigado, las'sales disueltas van hacia la zona radicular, produciendo quemaduras y clorosis en hojas y acelerando la senescencia de las plantas. Se ha detectado que la salinidad decrece comúnmente a medida que se aleja del mar, hasta llegar a niveles bajos no estresantes lo cual ocurre frecuentemente en suelos ubicados a altitudes de 900 $1000 \mathrm{msnm}$. Asimismo, la textura es franco-arenosa a nivel del mar y va aumentando gradualmente en el contenido de arcilla. Esto involucra consecuentemente el incremento de la capacidad de campo del suelo o la retención de agua en el suelo, disminuyendo de esta manera el estrés hídrico en los cultivos. En general los suelos áridos-salinos de la costa tienen muy bajo porcentaje de materia orgánica y son deficientes en fósforo y nitrógeno.

\section{BASES GENÉTICAS DE LA ESTRATÉGIA DE ADAPTACIÓN Y AVANCE DE SELECCIÓN}

La principal estrategia genética en la adaptación de clones superiores y familias híbridas de papa para tolerancia a salinidad y otros estreses abióticos relacionados con las zonas áridas es la generación de nuevas poblaciones por un sistema cíclico de selección recurrente que permita llegar a las siguientes metas:

- Mantener una amplia base genética para resistencia a estreses abióticos.

- Incrementar los genes que gobiernan la precocidad, resistencia al calor y la sequía.

- Incrementar la frecuencia de genes de resistencia a RKN (Meloidogyme).

- Seleccionar familias TPS y clones parentales TPS promisorios, adaptados a fotoperiodos cortos, largos e insensibles al fotoperiodo.

- Buscar la combinación favorable de atributos agronómicos con la calidad para el procesamiento industrial.

- Utilizar progenitores con buena habilidad combinatoria para resistencia a estreses abióticos.

- Incorporar en las familias y clones híbridos genes de inmunidad a los virus PVX y PVY.

El presente proyecto se ha concentrado en el grupo de genes de adaptación, los cuales son mayormente poligénicos y al final son los que determinan la adaptación de familias y genotipos a los estreses abióticos como la salinidad, calor, sequía, toxicidad de boro, sensibilidad al fotoperiodo y aún la precocidad. En este sentido, la generación de una familia promisoria TPS o de un clon élite con gran potencial de rendimiento ha sido el resultado de una combinación favorable de los genes aditivos y epistáticos.

\section{ADAPTACIÓN DE FAMILIAS HÍBRIDAS DE SEMILLA BOTANICA (TPS) A ZONAS ÁRIDAS}

\section{ENSAYOS PRELIMINARES CON FAMILIAS TPS}

Como parte de la estrategia de selección se inicia dentro del proyecto colaborativo los experimentos conducentes a la adaptación de líneas o híbridos de semilla botánica de papa a las zonas áridas y salinas del sur del Perú desde inicios de 1986. En ésta primera etapa se evaluaron 63 familias híbridas con un total de 17000 genotipos o seedlings. Los estreses de calor 
y salinidad dañaron a las plantas trasplantadas en éstos suelos regados por gravedad o inundación parcial. No se seleccionó ninguna familia promisoria, sólo unos cuantos genotipos que sobrevivieron y lograron tuberizar. Estos clones promisorios iniciales fueron multiplicados y sometidos a las pruebas serológicas de resistencia a virus y multiplicadas en invernadero para evaluaciones en experimentos de campo.

A principios de 1991 se ensaya otra estrategia de evaluación de familias de semilla botánica (TPS), con progenies cuyos clones parentales habian sido previamente seleccionados en zonas áridas por su tolerancia a estreses abióticos. El experimento fue conducido en suelos áridos moderadamente salinosy utilizando riego por exudación. De diez familias evaluadas se observó que la familia promisoria C89.437 x ST.BULK, mostraba una mayor frecuencia de genotipos adaptados con caracteres agronómicos deseables, seguida de la familia $387776.3 \times$ ST.BULK. En ambas familias el progenitor masculino fue una mezcla de polen de varios clones tolerantes a estreses abióticos.

En un intento de identificar familias de TPS con buena performancia agronómica se experimenta a principios de 1994 un nuevo set de híbridos superiores TPS en zonas áridas, con suelos ligeramente salinos en diseños avanzados y a una altitud de $900 \mathrm{msnm}$. Cada familia TPS fue experimentada asociadamente con su correspondiente familia-tubérculo (ST) dentro del diseño experimental. Las familias TPS que más sobrevivieron a los estreses abióticos fueron SERRANA $\times$ LT.9 y LT.9 $\times$ TS.9. Sin embargo, las familias tubérculos, de primera generación clonal, mostraron mayor adaptación a los estreses. Los híbridos de mayor performancia agronómica fueron CHIQUITA x TS.4 y SERRANA x LT.7. En términos de rendimiento, ninguna de las familias de tubérculos - TPS superó en rendimiento a la variedad COSTANERA usada como control. La familia TPS.SERRANA X LT.7 parece mostrar una adaptación a las condiciones áridas, sin embargo, sería necesario descartar experimentalmente alguna correlación positiva existente entre el efecto de estrés abiótico y la mayor producción de glicoalcaloides en los tubérculos de papa provenientes de SERRAMA x LT.7

En el verano de 1995, bajo condiciones de alta temperatura y fotoperiodo largo, se evaluaron diez familias de tuberculillos (ST) provenientes de semilla botánica (TPS). Los tuberculillos fueron sembrados en suelos áridos y ligeramente salinos, a $900 \mathrm{msnm}$. Las plantas mostraron un alto vigor ( 7 a 9) en el follaje, similar al vigor observado en los controles usando tubérculos normales de las variedades Tacna y Costanera. Asimismo todas las familias mostraron follaje, ausente de sintomas de enfermedades viróticas. La sobrevivencia de las plantas fue del $90 \%$ en contraposición de las plántulas de semilla botánica anteriormente evaluadas (cerca del $40 \%$ de sobrevivencia). La mayor performancia agronómica en la producción de tubérculos fue observada en la familia SERRANA x LT.7, con una alta uniformidad en color, forma y tamaño y con un rendimiento de $564 \mathrm{gr} / \mathrm{planta}$. En segundo lugar se registra el hibrido LT.9 x 104.12 LB con un rendimiento de $528 \mathrm{gr} /$ planta, pero la calidad comercial de los tubérculos fue inferior. Ambos hibridos provienen de parentales tolerantes al calory con genes de resistencia de campo a los virus PVX, PVY y PLRV.

Los resultados de estos experimentos preliminares de campo con familias TPS yST mostraron una posible alternativa del uso de la semilla botánica (TPS) y tuberculillos de primera generación clonal (ST.1.) en la producción comercial de papa en zonas áridas con estreses abióticos edáficos moderados.

\section{EVALUACIÓN DE FAMILIAS HÍBRIDAS (TPS) PROMISORIAS}

Con la finafidad de-determinar la performancia agronómica e identificar clones o genotipos promisorios dentro de cada familia, se tamizó 15 familias TPS bajo condiciones de suelos áridos muy salinos y con niveles medios de boro tóxico durante el invierno de 1995. Los progenitores de las familias TPS fueron seleccionados en Tacna por su tolerancia a salinidad, sequía, calor, precocidad y resistencia a RKN. Se utilizó como control, la semilla de polinización libre de la variedad Tikahuasi susceptible a salinidad. Los resultados de éste experimento nos darian también alguna información sobre la habilidad combinatoria para salinidad y sequía de algunos clones parentales. Se utilizaron 80 genotipos por familia. La conductividad eléctrica del terreno experimental fluctuó entre 15-18 mmhs. y el contenido de boro 3-9 ppm. antes del riego. Mayor sobrevivencia al trasplante después de 15 dias fue observada en las familias TPS, SDC89.315 x ST.BULK con $72 \%$, SDC89.302 $x$ SDC89.315 con $71 \%$ y SDC90.259 x ST.BULK con $65 \%$ de sobrevivencia. El control Vr. Tikahuasi (TPS) mostró muy baja sobrevivencia (14\%). La segunda 
evaluación de sobrevivencia realizada a 60 días, después del transplante, mostró solamente mayor frecuencia de plantas sobrevivientes con un vigor promedio de grado 3 , (no se registró mayor vigor) en las siguientes familias promisorias: SDC91.934 $\mathrm{x}$ SDC89.315 con 36\%; C90.259 x ST.BULK con $30 \%$ y SDC89.308 x ST.BULK con $27 \%$ de sobrevivencia. Sin embargo, no hubo una correlación positiva en la frecuencia de supervivencia y la capacidad de tuberización y producción de tuberculillos de buena calidad. Se logró identificar a las familias con mayor frecuencia de producción de tuberculillos de calidad: SDC90.259 x ST.BULK, SDC91.934 x SDC89.315 x SDC89.315 x ST.BULK y SDC91.902 x SDC89.315.

Del tamizado de estas 15 familias surgió que los clones élites utilizados como parentales SDC89.315, SDC90.259 y SDC90.260, podrían tener una buena habilidad combinatoria para resistencia a suelos muy salinos, debido a que proporcionan en la primera generación mayor frecuencia de híbridos o genotipos resistentes a salinidad. Las mejores combinaciones para suelos muy salinos fueron: SDC90.259 x ST:BULK, SDC91.934 x SDC89.315 y SDC89.315 x ST:BULK. El clon élite SDC89.315 de alta tolerancia al calory salinidad e inmune a los virus PVX y PVY parece comportarse como buen combinador para tolerancia a estreses abióticos. Cerca de 150 genotipos promisorios fueron seleccionados para multiplicación, ensayos avanzados, pruebas de ELISA. Estas pruebas fueron realizadas en La Molina-Lima bajo condiciones de invernadero y en suelos no estresados.

Una nueva estrategia en la producción comercial de papa a partir de semilla botánica (TPS) es aplicada a mediados de 1995 en zonas áridas con estreses abióticos edáficos moderados. Se seleccionaron previamente un grupo de diez híbridos superiores, cuyos progenitores se ásumia que tenian una buena habilidad combinatoria para atributos agronómicos, y cuyas semillas híbridas fueron seleccionadas por su alta calidad de embriones (vigorosos y bien formados). El potencial genético de estos hibridos fue puesto a prueba en suelos áridos y ligeramente salinos, bajo condiciones de baja temperatura y fotoperiodo corto, en Pachía Tacna (950 msnm.). El material fue trasplantado de almácigo al campo y el follaje fue cortado a los 80 dias a fin de determinar su precocidad. Se evaluó la sobrevivencia y el vigor del follaje a los 60 días del trasplante, habiéndose detectado lo siguiente:

a) Una alta frecuencia de sobrevivencia de las plantas trasplantadas. b) Un incremento conspicuo en el vigor de las plantas en las familias. En algunas familias se observó un grado de vigor 9 .

c) Una mayor frecuencia de genotipos con una arquitectura de planta ideal para ser usados, como clones promisorios o como futuros parentales para generar nuevas familias hibridas en zonas áridas.

Las familias TPS que más destacaron por su performancia general agronómica fueron: MF-Ix TS.5, MF-II X XY.13, y MF-II XTS.13. De estos tres híbridos promisorios se seleccionaron 57 genotipos por la arquitectura ideal de la planta, tuberización temprana y hábito de crecimiento determinado, los cuales fueron evaluados bajo condiciones de baja temperatura y días largos de verano en la sierra en Huancayo (3300 msnm.), mostrando una marcada desadaptación a las condiciones de la sierra.

\section{EVALUACIÓN DE FAMILIAS TPS BAJO CONDICIONES SEMIARIDAS}

Con la finalidad de evaluar las alternativas de la producción comercial de papa a partir de semilla botánica en la zona semiárida y altoandina de Tarata, a $3100 \mathrm{msnm}$., y con alta radiación solar, se estableció dos experimentos. El primer experimento se realizó durante la primavera-verano, con dos poblaciones de tubérculos familias (ST) provenientes de TPS cosechados y seleccionados en La Molina, Lima, en suelos no estresados. El vigor del follaje observado fue moderado en ambas poblaciones, FK.69 x CEW.69, y SERRANA x TS.9. Durante la cosecha se observó una gran diferencia de producción de tubérculos en ambos hibridos. Solamente el híbrido CFK.69 x CEW 69.1 presentó buena performancia agronómica.

El segundo ensayo se realizó en plena temporada de verano, y con riego adicional debido a la escasa precipitación fluvial (no mayor de $300 \mathrm{~mm}$ ). Se diseñó el experimento para determinar la performancia agronómica de 61 familias híbridas de TPS con genes de alta precocidad, resistencia a virus y a la rancha en la papa (Phytophthora infestans). Debido a la poca emergencia de plántulas en las bandejas de germinación, nueve familias fueron descartadas. La germinación y emergencia de las plántulas, hasta llegar al tamaño de transplante $(+10 \mathrm{~cm})$, fue de 50 días; es decir, 20 días más que en la costa, debido a las bajas temperaturas. El periodo de crecimiento fue de 90 días. Se observó un vigor moderado en el follaje de 
las familias y una gran variabilidad intra e interfamilias para la susceptibilidad al ataque del tizón temprano de la papa: Alternaria solani, el cual se presentó en la última etapa de desarrollo de las plántulas. Asimismo, a los 70 días después del trasplante hubo incidencia de heladas tempranas que afectaron a un $30-40 \%$ en las plantas, acelerando su senescencia. De una población total de 5200 genotipos evaluados, se seleccionaron 193 genotipos promisorios. Las siete mejores familias que tuvieron una performancia agronómica moderada bajo éstos estreses y mostrando un vigor de 5-7, frente a los demás fueron: TS. $6 \times 104.12$. LB, TS. $11 \times 104.12$. LB, TS. $14 \times$ 104.12.LB, LT.8 x R.128.6, ATZIMBA x R.128.6, MFII $x$ 104.12.LB, y LT. $8 \times 104.12$.LB. Los progenitores femeninos aportaron genes de gran precocidad $y$ tolerancia al calor, en cambio los progenitores masculinos, como 104.12.LB, aportaron genes de resistencia a la rancha de papa (Hytophthora infestans). Estos resultados nos indican que la siembra y transplante de TPS en la zona altoandina, deberia hacerse más tempranamente y en dos campañas agrícolas; es decir, octubre-diciembre y enero-marzo, con el mismo grupo de familias TPS para determinar su estabilidad.

\section{EVALUACIÓN DE FAMILIAS TPS EN DIFERENTES FOTOPERIODOS}

En suelos no estresados y con alta tecnología de manejo del cultivo y bajo condiciones de mediana temperatura y fotoperiodo corto, en la Estación experimental de La Molina-Lima, se evaluaron 53 familias hibridas TPS para el rendimiento y la calidad de los tubérculos a los 90 dias. En la cosecha se seleccionaron únicamente las tres familias de mejor rendimiento y uniformidad en los tubérculos. Estas familias seleccionadas: TS. $9 \times$ TPS. 67, TS. $14 \times$ TPS 67 y TS. $9 \times$ XY.4, ya en forma de tubérculos ST de primera generación clonal fueron sembradas en las zonas áridas y suelos semisalinos de Tacna, Pachía, en un diseño experimental junto con el control vr. Desiree. La mayor performancia agronómica, bajo condiciones de otoño con baja temperatura y fotoperiodo corto, fue observada en el híbrido TS.9 $x$ XY.4 con alta precocidad, vigor y rendimiento. Esta familia superó en rendimiento y calidad del tubérculo a la variedad Desiree utilizada como control, a pesar de mostrar un grado moderado de segregación para el tamaño del tubérculo.

Se estableció un experimento bajo condiciones de baja temperatura y fotoperiodo corto en suelos áridos y con niveles moderados de salinidad y toxicidad de boro para evaluar 63 familias híbridas TPS a 900 msnm. Pachía - Tacna. Se detectó una variabilidad genética en relación al vigor del follaje, que en general fue de mediana a alto. Los estreses abióticos moderados durante la conducción del experimento, incluidos el de riego ligeramente restringido y la ocurrencia del ataque temprano de Alternaria solani, afectaron grandemente en el rendimiento y calidad de los tubérculos en la mayoria de las familias híbridas evaluadas. Sin embargo, bajo estos estreses fue posible identificar cinco familias híbridas adaptadas a estas condiciones con buen rendimiento y calidad de tubérculos: Atzimba $x$ TPS.67, HPSI/113, TS. $14 \times$ TPS. 67, TS. $5 \times$ TPS. 67 y TS 14 x 104.12.LB las cuales superaron en rendimiento y calidad a la variedad Deriree usada como control.

Un total de once familias híbridas de TPS fueron evaluadas en La Vilcas, Tacna, a 550 msnm., bajo condiciones de baja y mediana temperatura, y dias cortos a días largos, en suelos áridos con niveles moderados de salinidad y toxicidad de boro. Alta segregación para la sobrevivencia promedio y vigor del follaje fue observada en nueve familias. Mayor frecuencia de sobrevivencia, vigor del follaje y rendimiento de tubérculos por planta fue registrada en los híbridos: MF I x TPS.67, 11035 x TPS.113, y TS. 6 x TPS.113. Un total de 26 genotipos promisorios fueron seleccionados para una evaluación más avanzada en rendimiento y sistema reproductivo en Tacna y Huancayo.

Bajo condiciones de fotoperiodo largo y alta temperatura en Calana, Tacna, a $650 \mathrm{msnm}$. se condujo un nuevo experimento con 42 familias híbridas de TPS, en suelos áridos con niveles medianos de salinidad, toxicidad de boro y riego ligeramente restringido. Un total de 2520 genotipos agrupadas en 42 familias fueron evaluadas por su performancia agronómica general. Sin embargo, a mediados del periodo de crecimiento de las plantas, se presentó un fuerte ataque de la nueva plaga de insecto (Russelina solanicola, Psilidae) la cual produjo daños marcados al follaje, sobre todo a los brotes, limitando el desarrollo normal de las plantas. La aplicación continua de insecticidas químicos disponibles en el mercado local no fue efectivo en el control de ésta plaga. A pesar de un ambiente favorable para el desarrollo del nemátodo (RKN) no se registró ataque en los tubérculos en ninguna familia 
ni en la variedad Costanera usada como control. Solamente seis familias híbridas de un total de 42 fueron identificadas como tolerantes a estos estreses con rendimiento ligeramente inferiores a la vr. Costanera: TS. $9 \times$ XY. 4 , TS. $9 \times$ TPS. 67, TS. $5 \times$ TPS. 113 , TS. $5 \times$ TPS. 67 , TS. 14 x TPS. 67, y TS. 14 x TPS.13.

Un experimento demostrativo en chacra de agricultor, usando dos familias de tubérculos ST fue conducida junto con el mismo agricultor, en suelos áridos con niveles bajos de salinidad y boro, y riego normal, en Pachía, Tacna, a $1000 \mathrm{msnm}$. Casi todo el periodo de crecimiento estuvo comprendido en días cortos de invierno y baja temperatura. Estas dos familias fueron alternadas en el experimento con la variedad Desiree. En general, el vigor de las plantas en ambos híbridos, asi como en la vr. Desiree, fue marcadamente alto (9) y libre de síntomas de enfermedades viróticas. Sin embargo, durante la cosecha a los 90 días de la siembra, se observó una marcada diferencia. Las plantas del híbrido MF I x Katahdyn mostraron una buena performancia agronómica en términos de rendimiento y uniformidad de tubérculos de valor comercial. El rendimiento del híbrido MF I x TS.5 fue muy bajo con una alta segregación por el tamaño y forma de los tubérculos. El rendimiento y calidad de Desiree fue mayor que MF I x TS.5, pero menor que MFI x Katahdin. Un total de 40 genotipos promisorios fueron seleccionados para evaluaciones futuras de rendimiento y habito reproductivo.

Con la finalidad de demostrar al agricultor la alternativa de producir papa comercialmente, usando familias de tubérculos TS provenientes de semilla botánica TPS, se ensayaron con 17 familias, previamente seleccionadas durante el cultivo de primavera. Este ensayo fue conducido con la participación activa del agricultor dueño de la chacra, en Pachía-Tacna a 1000 msnm. y en suelos áridos, con niveles bajos de salinidad y toxicidad de boro. en la época de invierno, con bajas temperaturas y fotoperiodo corto. En general todas las familias hibridas mostraron un crecimiento acelerado y buen vigor del follaje, sin síntomas de enfermedades viróticas. Durante la cosecha realizada a los 90 dias de la siembra, se identificó nueve familias muy promisorias con buena performancia agronómica en rendimiento y calidad comercial de tubérculos. Estas familias superaron en performancia a la variedad precoz Desiree y al clon élite tolerante a estreses abióticos SDC 92.085 (Granola x XY.20), ambos usados como controles. Los híbridos que más destacaron fueron: TS. $9 \times$ XY.13, TS. $9 \times X Y .4$, Serrana x TS.5, e I.1035 x TS.5.

\section{EVALUACIÓNDEFAMILIAS TPS CON CLONES ELITES Y VARIEDADES}

Tres familias de tubérculo seleccionados durante el invierno de familias TPS fueron evaluadas junto con clones élites y variedades tolerantes a estreses abióticos, en chacra de agricultor, en Calana, Tacna a $650 \mathrm{msnm}$. Como control positivo fue usada la vr. Desiree y como control negativo la vr. Tomasa. El experimento fue conducido en BCR con cuatro repeticiones en suelos áridos con niveles moderados de sal y boro, con altas temperaturas de verano y fotoperiodo largo. A mediados del periodo de crecimiento de las plantas, se presentó un ataque del insecto Psílido Russeliana solanicola que causó daños al follaje y a los brotes de genotipos susceptibles, detectándose una variabilidad genética para susceptibilidad a Russeliana. Las plantas susceptibles además del daño al follaje, mostraron luego de dos a tres semanas del ataque, síntomas de enfermedades viróticas, tales como clorosis, enrrollamiento de hojas, enanismo y encrespamiento de las hojas y en muchos casos pigmentación de antocianinas en el borde de las hojas apicales. Estos sintomas parecian indicar que el insecto Russeliana era un vector efectivo de esta enfermedad de la papa. Actualmente esta siendo integralmente investigada por el científico - virólogo Dr. Luis Salazar, del Centro Internacional de La Papa. Alta frecuencia de genotipos susceptibles a Russeliana fue detectada en la familia Aracy x TPS.113, mediana frecuencia en CEW 69.1 x TPS.113, y alta frecuencia de resistencia en TS. 9 x TPS.67. Los clones élites resistentes a estreses abióticos que más susceptibilidad mostraron tanto a Russeliana como a la enfermedad con síntomas parecidos a virosis fueron: SDC 92.085, SDC 92.023, SDC 92.140, y la vr. Tacna. Sin embargo una moderada resistencia de campo a Russeliana y a la enfermedad virótica fue observada en los clones élites: SDC 92.132, SDC 89.315, y en las variedades Basadre, y Primavera .

Tres Familias de tubérculos seleccionadas de familias TPS en verano bajo ambientes ligeramente estresantes fueron tamizados para resistencia a sequía y salidad con niveles medianos de boro tóxico junto con clones élites y variedades tolerantes al calor y a la salinidad. El experimento fue conducido con riego por exudación (cintas exudantes) en suelos 
franco - arenosos a nivel del mar, en la época de otoño-invierno, en la EEA La Yarada, Tacna. Un total de 100 genotipos (tubérculos) distribuidos en cuatro repeticiones fueron evaluados en las familias LT.8 $\mathrm{X}$ 104.12.LB y MF II x XY.13. El tercer grupo de familia ST estaba constituida solamente por 25 tubérculosclones, cada uno previamente seleccionado de plantas promisorias de diferentes familias TPS cosechadas durante el verano. Los estreses abióticos edáficos y posiblemente el fotoperiodo corto, afectaron grandemente a todas las plantas o genotipos de las dos familias-tubérculo. De los clones-tubérculos se seleccionaron cinco clones tolerantes a estreses abióticos y fueron descartados 20 por su susceptibilidad. Los clones seleccionados están siendo evaluados en Huancayo y Lima en su performancia agronómica y sistema reproductivo. Se observó una amplia variación en rendimiento y calidad entre los clones élites y variedades tolerantes a estreses abiótcos. Los clones élites SDC 92.023, SDC 89.315 y la variedad Basadre fueron las que mostraron mayor estabilidad en la tolerancia a los estreses edáficos y fueron clasificados como alta calidad para la agroindustria. Minitubérculos de 1 a $1.5 \mathrm{~cm}$ de diámetro de 11 familias TPS generados en bandejas de plástico bajo condiciones de invernadero fueron sembrados en el campo con la finalidad de determinar su potencial de desarrollo y rendimiento en suelos áridos con estrés moderado y riego por gravedad. El experimento se condujo en la EEA La Villa, del Valle de Moquegua, a 1400 msnm., alta radiación solar, alta temperatura y días largos. Las familias que presentaron mayor porcentaje de sobrevivencia y vigor del follaje (7-9) fueron MF II x TPS.13 (79\%), Atzimba x TPS.67 (79\%). Sin embargo la familia TS.6 $x$ TPS.13 con baja sobrevivencia (48\%) ocupó el primer lugar en el rendimiento y calidad de tubérculos por planta seguido de la familia TPS. 7 x 104.12.LB.

\section{EVALUACIÓN DE FAMILIAS HÍBRIDAS DE TPS DURANTE LAS CONDICIONES CLIMATICAS DEL FENÓMENO EL NIÑO}

Durante el verano de 1997 un total de 15 familias TPS fueron sembradas y trasplantadas a suelos áridos y con niveles moderados de salinidad y boro, en Pachía a $900 \mathrm{msnm}$., bajo condiciones de alta temperatura y fotoperiodo largo. En general las familias mostraron un alto vigor del follaje, sin embargo hubo diferencias significativas de sobrevivencia de las plántulas al transplante así como en el rendimiento. Las mejores familias TPS en rendimiento y calidad del tubérculo fueron MF-II x C94H-06.4; TPS-15 x TPS-67 y Cruza$155 \times$ TPS-67. Estas familias rindieron un poco por debajo de la Vr. Costanera usada como control.

Un total de 50 familias híbridas de tubérculos (ST.1) fueron evaluados en un diseño avanzado en suelos áridos con bajos niveles de salinidad y boro y bajo condiciones de invierno, con días cortos y mediana a alta temperatura y una densa y frecuente presencia de neblina, a 950 msnm. Se observó una uniformidad en el rápido y vigoroso desarrollo del follaje en todas las familias. A partir de los 70 días de crecimiento hasta la cosecha a los 90dias se presentó un ataque de rancha (Phytophthora infestans) en el campo experimental, mostrando las familias diferentes respuestas a ésta enfermedad. Esto permitió la identificación preliminar de 17 familias promisoriamente resistentes a la rancha y de éste grupo siete familias significativamente resistentes. Durante la cosecha, un total de 13 familias mostraron buena performancia agronómica y superaron al control Vr. Desiree en rendimiento y calidad del tubérculo. De éste grupo las siguientes familias mostraron también alta resistencia de campo a Phytophthora infestans:

\begin{tabular}{|l|l|l|}
\hline FAMILIA TPS & g/p & LB \\
\hline 1. AL-204 $\times$ TPS-67 & 767 & 3 \\
2. I-931 $\times$ TPS-13 & 686 & 2 \\
3. I-1085 $\times$ TPS-13 & 674 & 1 \\
4. Serrana $\times$ C94H-06.6 & 658 & 3 \\
5. CEW-69.1 $\times$. TPS-67 & 642 & 2 \\
6. C95-NN1 $\times$ TPS-13 & 617 & 2 \\
7. CFK-69.1 $\times 104.12$ LB & 602 & 2 \\
8. Serrana $\times$ C94H-06.4 & 541 & 2 \\
9. Aracy $\times$ TPS-67 & 527 & 3 \\
10. DESIREE (control) & 525 & 5 \\
\hline
\end{tabular}

Bajo condiciones de alta radiación solar en el valle de Moquegua a 1450 m.s.n.m., alta temperatura y dias cortos de invierno se tamizaron 20 familias tubérculos de TPS seleccionados en Tacna. Como control se usaron siete variedades y dos clones élites del CIP. Las condiciones ambientales fueron propicias para una fuerte ocurrencia poblacional de Russeliana solanicola, causando alto grado de daño al follaje y a los brotes (7-9) de las plantas en casi todas las familias y los nueve controles. Otro efecto nocivo fue acelerar 
el periodo de senescencia a los 70 dias de crecimiento. Solamente cuatro familias sufrieron menor daño (35) de Russeliana: y buen rendimiento de plantas cosechadas a los 100 días de periodo de crecimiento: $1-931 \times$ TPS-13, AL-624 x TPS-67, TS-15 x TPS- 13 y Serrana x C94.H06.4. Cerca de diez genotipos muy promisorios fueron seleccionados para pruebas futuras de rendimiento y resistencia a virus.

\section{PROSPECCIÓN FUTURA DE LA UTILIZACIÓN DE TPS EN ZONAS ÁRIDAS}

Hasta ahora los resultados promisorios de éstos experimentos, muestran la factibilidad de la producción de papa tanto para consumo como de semilla tubérculo (ST) de papa a partir de TPS libre de enfermedades viróticas en zonas áridas con estreses abióticos moderados. Sin embargo, es necesario ampliar la base genética de las poblaciones TPS para tolerancia a estreses abióticos en zonas áridas y para fotoperiodos cortos y largos, asi como altas y bajas temperaturas. Es necesario también ampliar la base genética para uniformidad de tamaño y forma, pues en general se ha detectado una segregación muy significativa dentro de cada familia, para los caracteres de tamaño y forma de los tubérculos. Esto ocurre con mayor frecuencia en familias TPS que en familias de tubérculos generados de TPS. Asimismo, es necesario identificar familias híbridas de TPS con moderada insensibilidad al fotoperiodo para su amplia adaptación y producción sostenida.

Los clones élites parentales deberían tener una habilidad combinatoria para precocidad, tolerancia al calor a niveles moderados de salinidad y sequía, características particulares que determinarian la adaptación y cultivo comercial de papa a partir de TPS en las zonas agroecológicas áridas y desérticas del tercer mundo. La utilización de clones tetraploides parentales $(2 n=4 x=48=$ AAAA) generados a partir de clones haploides $(2 n=2 x=24=A A)$ por poliploidización sexual con gametos 2 o por medio de duplicación somática cromosómica para producir familias superiores TPS se vislumbra como una nueva alternativa muy promisoria para la agricultura futura Clones élites tetraploides con excelentes atributos agronómicos y tolerantes a estreses abióticos. Estos clones serían haploidizados, mediante el uso polinizadores e inductores de haploides, como el caso del clon inductor IVP 35 , con la ayuda de marcadores genéticos de herencia simple que permite identificar las progenies diploides provenientes de la madre tetraploide. En realidad, estos clones diploides generados por el fitomejorador, desde el punto de vista citogenético son denominados dihaploides por tener dos sets o juegos de cromosomas básicos $X=12$ : y tienen la fórmula cromosómica: $2 n=2 x=24=A A$. Se hipotetiza que los clones progenitores tetraploides generados por poliploidización de los diploides altamente seleccionados por sus atributos agronómicos, fisiológicos y por su remarcable homocigosis tendrian el potencial genético de producir progenies híbridas uniformes y superiores de TPS. La variabilidad morfológica dentro de cada familia hibrida de TPS mostraría una mínima segregación fenotípica no detectable a simple vista durante la cosecha en el campo del agricultor. Esto aumentaría el valor comercial de los tubérculos cosechados en un período vegetativo de 90 días.

\section{ADAPTACIÓN DE NUEVOS CLONES Y PROGENITORES PROMISORIOS A ZONAS ÁRIDAS $Y$ SALINAS EN DIFERENTES FOTOPERIODOS}

Un aspecto importante dentro de la estrategia del presente proyecto ha sido la selección de clones superiores tolerantes a estreses abióticos, de temprana tuberización, resistencia de campo a los virus más comunes por tres a cuatro generaciones clonales de campo., así como una alta resistencia de campo a las razas virulentas del nemátodo del nudo de raíz Meloydogine incógnita, $M$. javanica y $\mathbf{M}$. arenaria. En este sentido, la selección de clones tolerantes a estreses abióticos, con buenos atributos agronómicos ha sido llevado a cabo año trás año. Los híbridos de los cruzamientos de parentales tolerantes a estreses abióticos y con resistencia a virus y RKN han sido tamizados en diferentes estaciones y fotoperiodos del año. A la fecha se tiene dieciséis clones superiores de una marcada estabilidad en performancia agronómica durante las cuatro estaciones del año ( $950 \mathrm{~g} / \mathrm{pl}$.), habiendo mostrado una relativa insensibilidad al fotoperiodo. Este logro podría significar la producción sostenida de materia prima fresca durante todo el año en la costa peruana para la agroindustria

En un intento de probar la resistencia de campo a virus de diez clones superiores con semilla de tercera a quinta generación, producida en zonas infestadas de áfidos, se realizó un experimento avanzado en chacra de agricultor. Desde el inicio del periodo vegetativo se observó los síntomas de virus en el 
follaje, habiendo detectado la resistencia de campo de los clones SDC 92.132, SDC 91.O19 y SDC 89.315. Los demás clones mostraron sintomas de virosis principalmente de PVX, PVY y PLRV. Posiblemente estos clones sean genotipos duplex (XXxx, YYyy) para resistencia a PVX y PVY, y tengan una mayor frecuencia de genes menores para la resistencia al virus PLRV. Estos clones también combinan la alta calidad industrial con precocidad y tolerancia al calor.

Bajo condiciones de la sierra semiárida de Tarata (3100 msnm.) y en días largos de primavera-verano se evaluaron un primer grupo de 30 clones avanzados, seleccionados por su tolerancia a suelos árido-salinos en la costa. Durante el cultivo experimental se presentó un fuerte ataque de Alternaria solani (SecaSeca) que afectó el follaje de la parte inferior y media de la plantas. Durante la cosecha realizada a los 90 días de la siembra y en presencia de cerca de 20 agricultores de la zona se logró seleccionar solamente el clon avanzado SDC 92. 019, con buen rendimiento y calidad del tubérculo. En enero de 1994 se establece nuevamente en Tarata ( $3100 \mathrm{msnm}$.) un experimento avanzado con 16 clones élites precoces y tolerantes al calor y cuatro variedades locales utilizadas como control. Se logró la identificación de cinco clones adaptados a las condiciones de la sierra peruana con los clones élites: SDC89.262, SDC89.315, SDC92.132, SDC92.145, SDC91.906, habiendo sido superado en rendimiento solamente por la variedad CICA. en un periodo de 90 días. La adaptación de estos clones superprecoces a las condiciones de la sierra peruana, permitiriá el cultivo de papa para consumo en primavera y en verano. Asimismo, catalizaría el establecimiento de un sistema sostenible de producción de semilla básica y certificada en la sierra para su comercialización y cultivo en la costa sur Peruana .

Bajo condiciones de días largos de verano, alta temperatura diurna y baja temperatura nocturna, se realizaron dos experimentos simultáneos en las zonas agroecológicas semiáridas de Ticaco (3300 msnm.) y Tarata (3100 msnm.), para determinar la performancia de 37 clones élites, incluidos los cinco clones anteriormente seleccionados en Tarata. La cosecha realizada a los 90 días de la siembra mostró el extraordinario rendimiento y calidad de tubérculos del clon SDC91.612 (Basadre), junto con los cinco clones élites anteriormente mencionados. Estos seis clones mostraron entre buena y alta calidad para procesamiento industrial.
Durante el verano de 1995, se evaluaron 34 clones promisorios bajo condiciones de altas temperaturas en suelos áridos, medianamente salinos a $550 \mathrm{msnm}$. en Tacna. Estos clones fueron seleccionados previamente de un grupo de 240 clones, en suelos muy salinos bajo condiciones de invierno y por su calidad para procesamiento industrial y resistencia a los virus PVX y PVY. Durante la cosecha se identificó como el mejor el clon SDC92.085, proveniente de un cruzamiento de GRANOLA por XY.20, con un rendimiento comercial de $923 \mathrm{~g} /$ planta y de un excelente valor comercial habiendo superado grandemente a las cuatro variedades usadas como control. El clon SDC92.085 hasta ahora ha mostrado en el tiempo y el espacio una estabilidad para calidad industrial, sin embargo parece ser sensible a fotoperiodos cortos de invierno de la costa.

Bajo condiciones de verano-otoño se evaluaron la performancia agronómica de 11 clones precoces y resistentes a estreses abióticos en suelos ligeramente salinos, intercalado con familias TPS. La semilla tubérculo utilizada fue de cuarta generación clonal producida en Tacna. El experimento fue conducido en Pachía a $1000 \mathrm{msnm}$. El follaje fue cortado a los 90 días después de la siembra. Durante la cosecha se determinó la gran performancia agronómica de los clones élites SDC91.640, SDC89.315, SDC91.906 y SDC91.612, los cuales superaron en rendimiento a los tres controles usados. Los clones SDC 91.906 y SDC 91.612 han venido mostrando a través de numerosos experimentos en chacra de agricultores, una consistente estabilidad en performancia agronómica general y una relativa insensibilidad al fotoperiodo y temperatura, por lo menos en suelos áridos de la costa media, entre 600 y 1000 msnm.

Se condujo un experimento en chacra de agricultor en la zona de Pocollay a $700 \mathrm{msnm}$. en suelos áridos ligeramente salinos, bajo condiciones de inviernoprimavera-1994. Se utilizaron 17 clones precoces élites y tres variedades usadas como control. La cosecha y evaluación de rendimiento y calidad de los tubérculos fue realizada a los 100 días después de la siembra. Seis clones mejorados SDC89.315, SDC89.262, SDC92.132, SDC92.640, SDC92.018 y SDC89.311 mostraron una extraordinaria precocidad y rendimiento con más de mil gramos de tubérculos por planta, habiendo superado a los tres controles utilizados: Desiree, Revolución y Peruanita y aún a las variedades de alta calidad industrial Tacna y Costanera. En la misma localidad de Pocollay se evaluaron once clones mejorados bajo condiciones 
de otoño-invierno 1995. Se utilizaron las variedades Desiree y Revolución como controles. Se determinó mayor rendimiento en los clones SDC91.514 (944 g/ p), SDC89.311 (889 g/p). Sin embargo, los clones SDC89.019 y la variedad Tacna mostraron rendimientos moderados pero con tubérculos de alta calidad en forma y tamaño (grado nueve).

A una alta presión de selección fueron sometidos clones élites y variedades tolerantes a estreses abióticos en un ambiente de campo infestado con poblaciones de la mosca minadora Lyriomiza widobrensis, en suelos árido-salinos y días cortos de invierno. En la Yarada media100 msnm. se observó un fuerte ataque y daño al follaje que generalmente estuvo en rango de mediano a fuerte $(5$ a 9 ) que afectó al rendimiento. Sin embargo se logró identificar al clon élite SDC 92.640 y a la nueva variedad Maria Tambeña con menos daño de Lyriomiza .

Durante la primavera de 1996, se estableció otro experimento con clones élites y avanzados en la Estación Experimental Agrícola de la Fundación Perú, Valle de Moquegua $1400 \mathrm{msnm}$. Se registró un fuerte ataque de poblaciones de la plaga de la papa relativamente nueva y desconocida de Russelianma solanicolsa (Psilido, Cigarrita ploma). Esta plaga causó un fuerte daño al follaje y sobre todo a los brotes limitando el desarrollo normal de la planta y reduciendo a menos de la mitad el área foliar. De los 21 clones o variedades evaluadas bajo fuerte ataque, se pudo identificar algunos que mostraron una tolerancia moderada a Russeliana y correlacionada al buen rendimiento del tubérculo, estos clones élites son: SDC 91.628 y SDC 91640 y la variedad María Tambeña. Se observó un menor ataque de Russeliana en la variedad tardía Tomasa, pero el rendimiento fue muy inferior. Parece indicar que las variedades 0 clones muy precoces y de mediana o poca área foliar son más susceptibles al daño causado por Russeliana solanicola.

El análisis de los resultados de más de 70 experimentos de campo, conducidos en las cuatro estaciones del año en las zonas áridas de Tacna, Moquegua y Arequipa, nos indican diferencias genotípicas en la performancia agronómica general y en el rendimiento y calidad de tubérculos en particular de los clones mejorados por efecto del fotoperiodo y la temperatura. Esto se presenta especialmente a $18^{\circ}$ de latitud sur. Sin embargo, se ha logrado determinar nueve clones mejorados en las zonas áridas como SDC91.640 y SDC91.612 (Basadre) que presentan una alta performancia agronómica en el tiempo y espacio, y son moderadamente insensibles a diferencias de fotoperiodo y temperatura. A la fecha se cuenta con 43 clones superiores de papa, adaptados a las condiciones áridas y salinas de la costa peruana, superprecoces y tolerantes al calor. La gran mayoría de los clones tienen alta calidad industrial para la elaboración de ojuelas, papa frita, papa semifrita congelada, almidón y harina. De este caudal de clones élites generados por este proyecto, siete presentan adaptación a condiciones semiáridas de la sierra a $3100 \mathrm{msnm}$. Asimismo, diez de éstos clones ya han sido introducidos al sistema de cultivo in vitro y a pruebas serológicas (ELISA) para la detección y eliminación de virus. Esto favorecerá enormemente la producción de plántulas y tuberculillos libres de patógenos para la distribución nacional e internacional de semilla.

\section{SELECCIÓN IN VITRO PARA RESISTENCIA A SALINIDAD}

Pruebas experimentales in vitro con diez clones avanzados de papa, han demostrado una correlación moderada entre la resistencia a salinidad en el campo y la resistencia a salinidad bajo condiciones de cultivo in vitro. Los clones que tienen una performancia agronómica bajo condiciones edáficas salinas hasta de 12 mmhs no sobreviven o se muestran muy latentes bajo condiciones in vitro a una concentración de 10 a $12 \mathrm{mmhs}$. La formación de callos en plantas y clones sobrevivientes parece ser un indicativo de reacción de resistencia al fuerte estrés de salinidad. Una de las limitaciones de los tamizados para resistencia a salinidad o toxicidad de boro bajo condiciones de cultivo in vitro son las diferencias clonales de respuesta al cultivo in vitro. Algunos clones de papa y camote presentan dificultades para su crecimiento y micropropagación. Los resultados de los experimentos sugieren un tamizado poblacional práctico para resistencia a salinidad bajo condiciones in vitro con concentraciones salinas de 6 a 8 mmhs.

\section{PRESIÓNDE SELECCIÓN PARA TOLERANCIA A TOXICIDAD DE BORO}

En un estado avanzado del presente proyecto, cuando se determinó una considerable ganancia genética, se sometió a la gran mayoria de los clones mejorados de papa, a evaluaciones y tamizados para tolerancia a estreses de toxicidad de boro y sequía. 
Los niveles elevados de boro en las zonas áridas de la costa peruana, como el caso de los valles costeros de Sama y Locumba, donde alcanzan niveles tóxicos de 10 a 14 ppm. el cual producen al igual que el estrés de salinidad, un efecto de crecimiento retardado, clorosis y quemadura del borde de las hojas de la planta de papa, asícomo enanismo y bajo rendimiento de tubérculos. Asimismo el efecto nocivo del boro tóxico se presenta en clones avanzados, tolerantes a salinidad y sequía. Es por eso que el ensamblaje de estos tres atributos de resistencia a sal, sequía, toxicidad de boro es necesario para la adaptación integral de los clones liberados a zonas agroecológicas áridas y salinas del trópico. En general los clones avanzados de papa, tolerantes a salinidad y sequía, seleccionados para las zonas áridas y salinas, presentan una moderada tolerancia a niveles tóxicos de boro que fluctúan de 4 a $6 \mathrm{ppm}$. Los experimentos con clones avanzados de camote y tolerancia a niveles tóxicos de boro entre 4 y $12 \mathrm{ppm}$. en los valle de Sama, Locumba e Ite muestran que existe una variabilidad genética, aunque en baja frecuencia, para tolerancia a la toxicidad de boro. Los experimentos con clones élites de papa todavía no se han realizado en éstas zonas debido a la falta de semilla limpia y presupuesto para conducirlos.

\section{PRESIÓNDE SELECCIÓN PARA TOLERANCIA A SEQUIA}

La vulnerabilidad de la papa ante los déficits de agua que ocurren durante su ciclo de crecimiento trae como consecuencia bajos rendimientos y mala calidad de los tubérculos. Esto pone en manifiesto el papel importante que juega el agua en la producción comercial (Ekanayake, 1994). Sin embargo la papa presenta variabilidad genética para resistencia a sequía, es decir algunos clones o variedades se desempeñan mejor que otras bajo el estrés de sequía. Con criterios de selección asociados a la resistencia a sequía se puede seleccionar y mejorar genotipos o clones adaptados a un medio agroecológico árido con estreses de sequía. El perjuicio que causa la sequía en la papa se ha descrito como consecuencia de:

a) La reducción del follaje productivo, escasa emergencia y escasa expansión foliar.

b) Reducción de la tasa de fotosíntesis por unidad de área foliar.

c) Reducción del período vegetativo o senescencia precoz. d) Reducción del rendimiento de tubérculos por planta.

e) Disminución de la calidad de los tubérculos (deformaciones y grietas).

Ekanayake planteó en 1994 una escala de apreciación del estrés por sequía basada en la marchitez foliar. Esta escala se viene actualmente utilizando para identificar clones tolerantes a estreses moderados de sequía desde el punto de vista de la producción de biomasa aérea. Sin embargo, durante la cosecha se aplica otra escala para la evaluación del rendimiento y calidad de los tubérculos y luego se trata de correlacionar ambos parámetros.

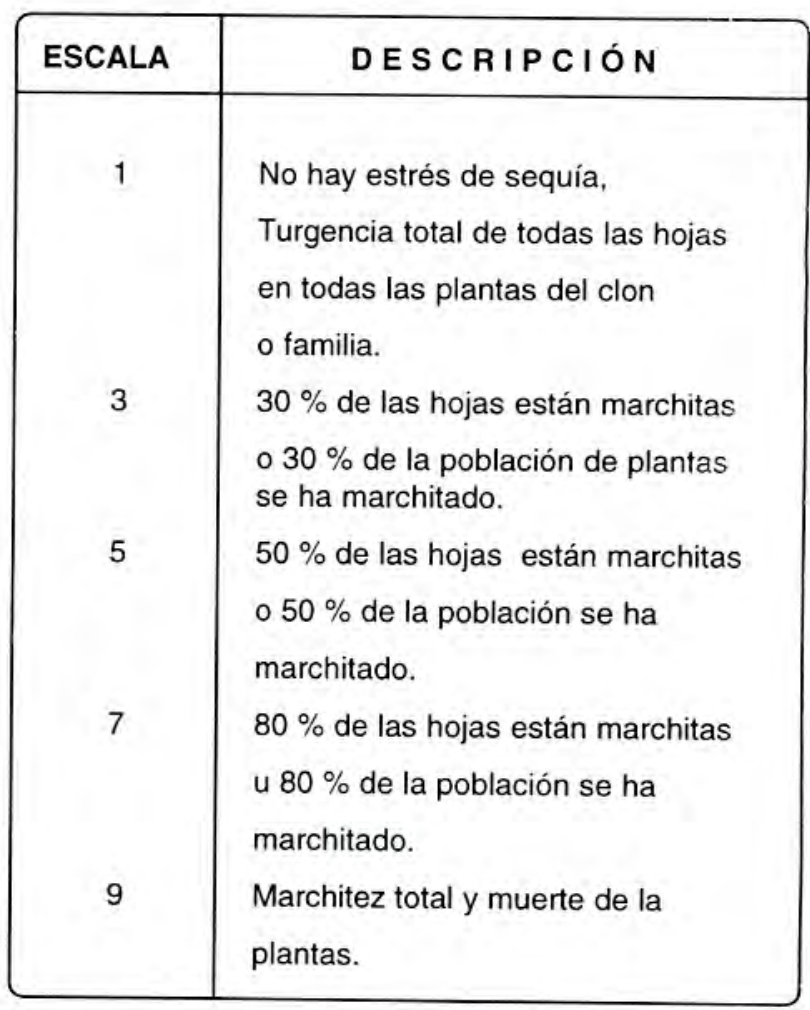

El germoplasma mejorado de papa hasta ahora obtenido muestra esa tolerancia al riego restringido frente a otras variedades conocidas. Los parámetros utilizados para determinar el grado de resistencia o tolerancia a sequía fueron el grado de senescencia del follaje, el rendimiento de tubérculos por planta, la calidad de los tubérculos (forma y tamaño) y la calidad industrial para procesamiento utilizando la escala de calidad (1-3-5-7-9). En numerosos experimentos conducidos con riego restringido se ha observado que el estrés de sequía incrementa moderada o fuerte- 
mente la salinidad de las parcelas con estrés de agua, factor que hace un poco más complicada la interpretación de los resultados. En la mayoría de los casos el vigor del follaje disminuye fuertemente a medida que se incrementaba el número de días de sequía en los clones susceptibles. En general, el follaje verde y medianamente vigoroso muestra una correlación positiva con el buen rendimiento de tubérculos y la tolerancia a sequia. En este sentido, todos los clones avanzados de papa, tolerantes a salinidad, también han sido sometidos a estreses moderados de sequía ó riego restringido, como parte de la estrategia para la adaptación general a zonas áridas, donde el recurso agua es escaso y restringido.

Bajo condiciones de dias largos y temperatura mediana a alta, durante la primavera y verano de 1995 , se condujo un experimento con 14 clones de papa, en suelos ligeramente salinos, franco-arenoso limoso. El experimento fue dividido en dos parcelas, una con riego normal, cada ocho días y la otra con estrés de sequía a partir de los 60 días, después de la siembra, con un periodo vegetativo de 90 días. La tolerancia a sequia fue determinada con el rendimiento y la calidad de los tubérculos por planta, así como la calidad industrial de hojuelas fritas. Los clones élites de buena performancia agronómica y calidad industrial bajo condiciones de estrés de sequía fueron: SDC 91.628, SDC 92.019, SDC 92.145 (Desértica) y SDC 91.612 (Basadre). En general se observó un incremento de la calidad industrial de los clones con el riego restringido. La variedad Tomasa Tito Condemayta, usada como control, ocupó el último lugar del rankin de rendimiento y calidad de tubérculos. Siete clones élites superaron en rendimiento a la variedad precoz y tolerante al calor bajo riego normal, sin embargo, la vr. Desiree ocupó el tercer lugar en tolerancia al estrés de sequía y con buena calidad para procesamiento industrial. Esta presión de selección a permitido en los numerosos experimentos obtener más de 20 clones elites con doble resistencia a tolerancia, salinidad y sequía. Es importante mencionar que estos clones elites tolerantes a sequia, con excepción de SDC 91.628, mostraron también adaptación a las condiciones semiáridas de la sierra de Tacna.

\section{RESISTENCIA A ALGUNOS ESTRESES BIOTICOS PREDOMINANTES EN ZONAS ARIDAS}

El la zona agroecológica árida de la costa peruana el cultivo comercial sostenido de variedades mejoradas tolerantes a estreses abióticos no tendría el éxito esperado si el germoplasma mejorado es susceptible a los estreses bióticos más comunes o predominantes de la costa. En este sentido, dentro de la estrategia de mejoramiento y adaptación de clones elites se ha logrado la obtención de algunos clones con potencial de rendimiento y con resistencia de campo a algunos estreses bióticos.

\section{RESISTENCIA DE CAMPO A NEMATODOS}

Elestrés biótico edáfico más importante en el cultivo de la papa, en zonas áridas y salinas de la costa peruana, es el ataque del nemátodo del nudo de la raíz, constituido por las poblaciones de tres especies, M.incógnita, M.javanica y M.arenaria. Durante la cosecha y evaluación de los experimentos de papa en el campo, los genotipos o clones susceptibles a estas plagas son eliminados en el programa de mejoramiento y adaptación. La indicación de susceptibilidad de la papa a Meloidogyne incluye ondulaciones en la raíz. necrosis, producción masal de huevos o quistes, rajaduras o deformaciones del tubérculo, clorosis y crecimiento retardado o enanismo y principalmente la reducción del rendimiento. Por eso es importante que cualquier clon mejorado o variedad de papa liberada, sea resistente a las razas virulentas de Meloidogyne. Estas tres especies de Meloidogyne parecen producir un sinergismo en el ataque a los cultivos de papa en la costa peruana (Jatala, 1978).

La selección de los genotipos parentales para cruzamientos se basa en la combinación de caracteres asociados a alto rendimiento, buena calidad comercial de tubérculos, tolerancia al estrés abiótico de sequia y salinidad y resistencia a Medaloidogyne (Jatala, 1978) plantearon la hipótesis de que existen factores genéticos comunes que controlan la resistencia a estas tres especies de Medaloidogyne. Por otra parte, los estimados de heredabilidad para la reacción a estas especies son altos. Asimismo, la frecuencia de resistencia a las pruebas de progenie indican que el desarrollo de variedades resistentes a ambas especies sería relativamente fácil. La experiencia en la costa sur peruana nos muestra que el nivel de la población de nemátodos, llega al máximo durante los meses de primavera y verano; es por eso que el tamizado óptimo de progenies y clones promisorios de papa se ha realizado entre noviembre y marzo. Los clones de papa antes de ser tamizados tenían previamente resistencia genética al calor. Durante la cosecha de 
cada experimento de papa, se selecciona primero, en el campo, los clones por su performancia agronómica general basada mayormente en el rendimiento y calidad de los tubérculos y luego en esta población seleccionada, se hace el tamizado y descarte de clones susceptibles al nemátodo. Asimismo se ha logrado seleccionar progenitores promisorios con buena habilidad combinatoria para resistencia a RKN.

\section{RESISTENCIA DE CAMPO A LOS VIRUS MÁS COMUNES}

Cerca de diez especies de átidos han sido identificados en los valles de Tacna y Moquegua que habitan mayormente en especies (8) de malezas halófilas muy comunes, que sirven como hospederos. Por otra parte, poblaciones de áfidos son detectadas en los cultivos y terrenos abandonados de papa, camote, ají, algodón, maíz y tomate. Esto origina una fuerte presión de población a los'nuevos cultivos de papa, produciendo una efectiva infección a los clones sometidos a evaluación para resistencia de campo a virus. Se ha observado que cualquier variedad o clon avanzado (que no es resistente a virus) cultivado en la costa sur peruana (Tacna, Moquegua y Arequipa), muestran síntomas de enfermedad virótica en la siguiente campaña, reduciendo el vigor y el rendimiento, mostrando una "degeneración" en la variedad. Al igual que el daño causado por el nemátodo, una variedad superior o familia TPS adaptada a las condiciones de aridez, salinidad, calor y con buenos caracteres agronómicos, no tendría durabilidad ni futuro sino tiene resistencia a los virus más comunes, en un medio agroecológico con alta infección virótica. La transferencia de genes de resistencia a los principales virus de la papa a clones superiores ha logrado generar clones mejorados, inmunes a los virus PVY y PVX y clones clones resistentes al virus PLRV. En este sentido, el germoplasma mejorado de papa para zonas árido-salinas involucra también algunos clones inmunes a PVY y PVX y resistencia de campo al virus del enrrollamiento de la hoja PLRV.

Durante los últimos seis años se ha sometido a 38 clones elites de papa, resistentes a estreses abióticos, a una fuerte presión de selección para resistencia a virus. Los clones fueron cultivados experimentalmente en chacras de agricultores durante tres, cuatro y hasta cinco generaciones clonales, sin reciclar la semilla en la sierra ni en invernaderos, es decir, se utilizó la misma semilla. La observación de los síntomas generados por los virus en papa, en los clones elites comparados con las variedades convencionales, se realizó en cada campaña. Se identificó 16 clones de alta resistencia de campo a los virus del mosaico $P V X, P V Y$ y cuatro clones altamente resistentes a los seis virus comunes, PVX, PVY, PVA, APMV, y APLV. Por otra parte las variedades convencionales usadas como control: Revolución, Mariva, Tomasa y Perricholi, mostraron alto grado de infección después de la 2da. y 3era. generación clonal de campo bajo condiciones de costa.

A pesar de éstos logros, hoy en dia estamos encarando frente a un nuevo problema fitosanitario con las poblaciones de la nueva plaga de papa surperuana llamada Cigarrita Ploma (Russeliana solanicola) la cual, además de producir daños al follaje, especialmente a los brotes, es un posible vector y transmisor eficaz de un fitoplasma de la papa. Las observaciones preliminares realizadas de la incidencia de ésta enfermedad en la costa sur peruana de Arequipa, Moquegua y Tacna, sugieren la existencia de una variabilidad genética para resistencia o susceptibilidad al fitoplasma en el germoplasma mejorado de papa, involucrando familias TPS, genotipos dentro de cada familia y clones elites.

\section{RESISTENCIA DE CAMPO A OTRAS PLAGAS INSECTILES Y ENFERMEDADES.}

Durante los últimos cinco años se ha puesic especial interés en monitorear la respuestas de clones variedades y de familias híbridas al ataque de la plagas insectiles más comunes de las zonas áridas, sobre todo del sur del Perú. Las condiciones climáticas reinantes durante el fenómeno de el Niño promovieron el ataque la alta ocurrencia de la rancha de la papa, la Cigarrita ploma, las Mosca Minadora y la Polilla de Papa en los cultivos de papa y campos experimentales del sur del Perú. Los experimentos de campo durante más de diez años y las observaciones durante el almacenamiento de la papa de las variedades mejoradas del Perú tanto de invierno como de verano (industriales), así como los clones promisorios y elites, familias híbridas de tubérculos provenientes de TPS nos muestran que no hay una variedad o clon élite de papa resistente a la Polilla de Papa (Throrimaea operculella). Bajo condiciones de campo y de almacén todas los genotipos conocidos son fuertemente dañados bajo la ocurrencia poblacional de esta plaga. El mejoramiento para resistencia a polilla siempre ha sido un cuello de botella para los fitomejoradores. Sin embargo, gracias al 
aporte de la Ingeniería genética se ha logrado transformar la Vr. Costanera resistente a la polilla tanto en campo como en almacén. Los resultados experimentales y en chacra de agricultor son muy promisorios.

Hasta ahora los resultados de las observaciones de campo usando una amplia base genética de papa nos indican una moderada resistencia de campo a la mosca minadora (Lyriomyza widobrensis) en solamente algunas variedades y clones elites entre ellos, la Vr. Maria Tambeña y el clon élite SDC89.315 (Calana). Al igual que el caso de la polilla, la Vr. Costanera transformada viene mostrando una consistente resistencia de campo a la Mosca Minadora en comparación con otro material susceptible no transformado.

Casitodas las variedades y clones elites sucumben al ataque de la cigarrita ploma (Russeliana solanicola). Se ha observado una moderada tolerancia en la Variedad Primavera y en el clon élite SDC89.315. Así mismo se ha observado genotipos segregantes resistentes al daño de Russeliana en algunas familias híbridas TPS. Durante los dos últimos años una alta presión de población ha sido detectada en los cultivos de papa en Arequipa, Moquegua y Tacna. Además del daño al follaje y brotes que causa, parece también transmitir una enfermedad parecida al virus que degenera al clon en poco tiempo. Por otra parte la amplia base genética usada para la adaptación del germoplasma de papa para zonas áridas y salinas de la costa, ha permitido identificar una marcada resistencia de campo bajo condiciones muy propicias y óptimas para el ataque de la rancha de la papa Phytophtora infestants en numerosos genotipos promisorios dentro de familias tubérculos (ST), en algunos clones elites, y variedades comerciales y en cerca de 15 familias híbridas TPS. Entre las variedades que han mostrado buena resistencia de campo se tiene Perricholi, Kori-INIA y Primavera. Más de 15 variedades conocidas y cerca de 30 clones elites del CIP han mostrado susceptibilidad a la rancha bajo las condiciones de densa neblina y alta temperatura durante el invierno de 1997 con el fenómeno de El Niño.

\section{MECANISMO DE RESISTENCIA GENÉTICA AL ESTRES ABIOTICO.}

Las diferencias genotípicas en la tolerancia a estreses abióticos, producidas por la salinidad y toxicidad del boro, se deben a la variabilidad genética en el grado de eficiencia de absorción y transporte de los iones en la planta. En este sentido, la tolerancia a la salinidad y toxicidad de boro, así como el estrés de sequía, son poligenéticamente controlados. La reacción a salinidad en papa y camote no es simple. Generalmente hay una correlación negativa entre tolerancia al calor y sequía con la tolerancia al frío. Por consiguiente, clones selectos para buena performancia en calor y sequía, no tienen buena performancia en frío y viceversa. El mecanismo de tolerancia de las plantas de papa a la salinidad, se debe a la resistencia de cambio en la ultra estructura de los cloroplastos de las hojas de la planta por el estrés de la sal que presumiblemente afectan a la performancia de asimilación y capacidad fotosintética de la planta y a la producción de carbohidratos. Asimismo, a la habilidad de las células de la planta a tolerar altos niveles de sodio. Según Epstien 1980, las diferencias en la captación o ingreso de iones, 0 transporte de ellos, es importante en el mejoramiento para tolerancia a salinidad.

El mejoramiento genético para tolerancia a salinidad, ha sido llevado a cabo exitosamente en otros cultivos. Bains y asociados (1971) encontraron que las líneas mejoradas de cebada, tolerantes a salinidad, tenían una reducción de $39 \%$ del rendimiento, cuando se aumentaba la salinidad de 8 a $34 \mathrm{mmhs} / \mathrm{cm}^{2}$. Bains desarrolló variedades de cebada que pueden ser irrigadas con agua de mar, con un rendimiento del $50 \%$ menor que el promedio nacional de la India. Epstein y C.Rick en (1976) y Rick (1982) reportaron la tolerancia a salinidad de híbridos introspectivos de tomate, que puedan dar frutos aceptables con 33\% de agua de mar. Epstein (1980) planteó la hjpótesis de que la resistencia a salinidad en el tomate está asociada a la habilidad de las células a tolerar altos niveles de sodio o translocación de los mismos. Epstein y Lauchli (1980) plantearon la hipótesis de que las diferencias a la captación o ingreso de iones, así como el transporte de ellos, es importante en el mejoramiento para tolerancia a la sal. A.Quinn (1980) reportó la selección de variedades de remolacha azucarera, tolerantes a salinidad para las zonas áridas de Estados Unidos. Quinn (1980) planteó la hipótesis que el mecanismo de resistencia a salinidad es debido a la exclusión selectiva de iones de sodio. De igual manera, se puede enumerar ejemplos de tolerancia a salinidad en variedades mejoradas de caña de azúcar y arroz en le sudeste de Asia tropical.

Analizando los planteamientos de Pomannperoma 
(1982) y de Epstein y Lauchli (1982), podemos concluir que las diferencias genéticas en la tolerancia al estrés edáfico, producido por la salinidad, acidez, toxicidad de boro, aluminio y hierro, se deben a la variabilidad genética de la especie cultivada en relación a cinco factores principales:

- La capacidad de absorción de iones por la raíz.

- Latraslocación de los elementos dentro del xilema.

- La retención de los iones en los tejidos adyacentes.

- La movilidad de los elementos del floema.

- La eficiencia en la utilización del metabolismo de iones.

Correlacionando estos principios, podemos decir que una plántula o un tubérculo brotado de papa plantada en suelos salinos, generalmente presenta los siguientes cuadros:

\begin{tabular}{|c|c|}
\hline CLASE & $\begin{array}{c}\text { REACCIÓN FENOTIPICA } \\
\text { DE LA PLANTA }\end{array}$ \\
\hline 1 & Sucumbe al ser trasplantado. \\
\hline 2 & $\begin{array}{l}\text { Emerge y sobrevive mostrando un } \\
\text { enanismo y clorosis. }\end{array}$ \\
\hline 3 & $\begin{array}{l}\text { Desarrollo de la planta, mostrando } \\
\text { quemaduras en los bordes de las } \\
\text { hojas y ninguna o muy poca } \\
\text { tuberización. }\end{array}$ \\
\hline 4 & $\begin{array}{l}\text { Desarrollo normal y vigoroso del } \\
\text { follaje pero muy poca o ninguna } \\
\text { tuberización. }\end{array}$ \\
\hline 5 & $\begin{array}{l}\text { Desarrollo escaso del follafe y } \\
\text { tuberización normal. }\end{array}$ \\
\hline 6 & $\begin{array}{l}\text { Desarrollo vigoroso del follaje y } \\
\text { tuberización normal. }\end{array}$ \\
\hline 7 & $\begin{array}{l}\text { Muestra un temprana } \\
\text { senescencia antes de los } 70 \text { días }\end{array}$ \\
\hline 8 & $\begin{array}{l}\text { Acumulación de glicoalcaloides } \\
\text { en los tubérculos. }\end{array}$ \\
\hline
\end{tabular}

Dentro de la estrategia del proyecto, los clones promisorios seleccionados han sido de clase 5 y 6 . La primera permite una mayor densidad de siembra y mayor rendimiento. La segunda (clase 6) permite una cobertura rápida y eficaz del suelo, con el consiguiente ahorro de humedad edáfica y fluctuación moderada de los niveles tóxicos de salinidad.

\section{VARIEDADES SUPERIORES DE PAPA DE CALIDAD INDUSTRIAL DISPONIBLES PARA LAS ZONAS ÁRIDO SALINAS DE LA COSTA PERUANA}

Las características agronómicas generales de las variedades superiores de calidad industrial liberadas para la agricultura de la costa peruana, se mencionan a continuación:

a) Tolerancia a los factores adversos de muchos suelos de la costa, tales como salinidad (6-13 mmh.) niveles moderados de boro (5-10 ppm.) y sequía parcial (riego restringido).

b) Potencial de rendimiento mayor de $20 \tan / \mathrm{ha}$. en un periodo vegetativo de sólo 90 días.

c) Resistencia en campo al nemátodo del nudo de la raíz.

d) Tolerancia al calor tanto de primavera como del verano. Por éste atributo los hace candidatos para su cultivo en el trópico medio y bajo.

e) Resistencia a los virus del mosaico de la papa PVX y PVY, al virus del enrrollamiento de la hoja (PRLV), muy comunes y virulentos en el extremo sur de la costa peruana.

f) Buena y excelente calidad industrial para procesamiento.

\begin{tabular}{|l|l|l|l|}
\hline \multicolumn{1}{|c|}{ VARIEDAD } & \multicolumn{1}{|c|}{ PEDIGREE } & \multicolumn{1}{c|}{$\begin{array}{c}\text { COLOR } \\
\text { PIEL }\end{array}$} & $\begin{array}{l}\text { COLOR } \\
\text { PULPA }\end{array}$ \\
\hline VR. COSTANERA & LT.1 $\times$ XY.BULK & crema & crema \\
\hline VR. TACNA & SERRANA $\times$ XY.4 & crema & crema \\
\hline VR. PRIMAVERA & B71.74.49 $\times$ XY.13 & crema & amarillo \\
\hline VR. DESERTICA & C $89.479 \times 3875521.30$ & crema & amarillo \\
\hline VR. BASADRE & MEX.XY.9 & crema & amarillo \\
\hline
\end{tabular}

VARIEDAD "COSTANERA"

Código Experimental : : Li-8 (CIP 379706.27)

Pedigree

: LT-1 $\times$ XY.bulk

El clon LT-1 utilizado como progenitor femenino posee una amplia adaptación en las zonas del trópico húmedo medio, muy buena tolerancia al calor, gran precocidad y tolerancia a la marchitez bacteriana. EI progenitor masculino $X Y$ bulk proviene de una mezcla de polen de clones inmunes a los virus $X$ y $Y$. Ambos 
progenitores fueron desarrollados por el departamento de Genética y Mejoramiento del Centro Internacional de la Papa.

\section{- Características de la planta}

Vigor

Altura

Nro de tallos

Hojas

\section{Pubescencia}

Flores

Bayas
Bueno.

$60 \mathrm{~cm}$.

4-5 por planta.

Verde claro con

foliolos medianos.

\section{Escasa.}

Blancas. Floración

escasa.

Muy eścasas o ninguna.

- Características del tubérculo

Estolones

Forma

Tamaño

Color de la pulpa

Ojos

Brotes

Nro. de tubérculos :

Periodo de latencia:
Muy cortos, tuberización compacta. Oval-elíptica a oblonga. Mediano a grande, a los 70 dias tiene tamaño comercial.

Crema.

Crema.

Superficiales.

Verdes, sin pigmentos.

Medio (8-10).

Corto (6 semanas).

- Calidad del tubérculo

Materia seca

Azúcar reductor

Calidad de hojuelas:

Color de hojuelas

Calidad de fritura
$21.6 \%$.

$0.05 \%$.

Muy buena.

Muy bueno (1.2).

Muy buena.

\section{- Resistencia a plagas y enfermedades}

Inmune a los virus $X y Y$, moderadamente resistente a PLRV y al nemátodo del nudo de la raíz, Meloidogyne incógnita, tolerante a marchitez bacteriana y moderadamente susceptible a los tizones temprano y tardío.

\section{- Resistencia a estreses abióticos}

Salinidad

Sequía

Calor

Toxicidad en boro :

- Período vegetativo

Muy precoz, 80-90 días.

\section{- Adaptación}

Costa peruana, trópico húmedo medio y bajo y sierrra media.

\section{- Época de siembra}

Por su tolerancia al calor se adapta para su cultivo en primavera, verano y otoño. Sembrar a principios de setiembre (primavera-verano) y a principios de marzo (otoño).

\section{VARIEDAD "TACNA"}

Código experimental : C90.17(CIP 390478.9)

Pedigree

\section{: Serrana X XY.4.}

Lá variedad argentina serrana, utilizada como progenitor femenino, se caracteriza por su alto rendimiento y resistencia al virus del enrollamiento de la hoja (PLVR). El progenitor masculino XY.4 es un clon mejorado del departamento de Genética y Mejoramiento del Centro Internacional de la Papa (CIP). Su principal atributo es su gran tolerancia a los virus PVX y PVY y su precocidad (80-90 días).

- Características de la planta

Vigor
Altura media
Nro de tallos
Hojas
Pubescencia
Flores
Bayas
Brotes

Número de tubérculos: Periodo de latencia

- Calidad del tubérculo

$\begin{array}{lll}\text { Materia seca } & : & 20.5 \% \\ \text { Azúcar reductor } & : & 0.05 \% \\ \text { Calidad de hojuelas } & : & \text { Buena. } \\ \text { Color de hojuelas } & : & \text { Buena (2.7). } \\ \text { Calidad de la fritura } & : & \text { Buena. }\end{array}$

\section{- Resistencia a plagas y enfermedades}

Inmune a los virus $\mathrm{X}$ y $\mathrm{Y}$, muy buena resistencia a PLRV, moderadamente resistente al nemátodo del nudo de la raíz, Meloydogyne incognita, y algo tolerante a la marchitez bacteriana. 
- Resistencia a estreses abióticos

Salinidad

Sequía

Calor

Toxicidad de boro

Alta $(6-10 \mathrm{mmh})$.

Media (riego restringido).

Alta (Prom.23-25 ${ }^{\circ} \mathrm{C}$ ). Media (5-10 ppm).

- Periodo vegetativo

Precoz, 90 dias.

\section{- Adaptación}

Esta variedad se adapta a las condiciones de la costa central y sur, y a la zona subtropical media.

\section{- Época de siembra}

Su tolerancia al calor la hace apta para cultivos en primavera, verano y otoño. Se recomienda sembrar a principios de setiembre (primavera) y a principios de marzo (otoño).

\section{VARIEDAD "PRIMAVERA"}

\section{Código experimental}

Pedigree

SDC 91.906,

CIP 392781.1.

El clon superior $B 71.74 .49$ generado por el Instituto Agronómico de Balcarce, Argentina, y usado cono progenitor femenino para generar este híbrido, es un clon de alto rendimiento y resistente al virus del enrollamiento de la papa (PLRV). El progenitor masculino XY.13 es un clon élite generado por el departamento de Genética y Mejoramiento del CIP, proviene de una familia híbrida muy precoz, tolerante al calor y con resistencia a los virus PVX y PVY. Las características de ambos progenitores fueron ensamblados para generar este clon superior, hoy variedad "primavera".

\section{- Características de la planta}

$\begin{array}{lcl}\text { Vigor } & : & \text { Muy alto. } \\ \text { Altura } & : & 60-80 \mathrm{~cm} . \\ \text { Tallos } & : & \begin{array}{l}5-6 \text { por planta. } \\ \text { Hojas }\end{array} \\ \begin{array}{lll}\text { Puberde oscuras, con } \\ \text { foliolos anchos. }\end{array} \\ \text { Flores } & : & \begin{array}{l}\text { Mediana. } \\ \text { Blancas, floración } \\ \text { abundante. }\end{array} \\ \text { Bayas } & : & \begin{array}{l}\text { Muy escasas o ninguna. } \\ \text { Fertilidad del polen: }\end{array}\end{array}$

- Características del tubérculo

\begin{tabular}{|c|c|c|}
\hline Estolones & & Cortos, medios. \\
\hline Tuberización & & Semicompacta. \\
\hline Forma & & Oval-redondeada. \\
\hline Tamaño & & Mediano a grande. \\
\hline Color de la piel & & Crema-amarillento. \\
\hline Color de la pulpa & & Amarillo oscuro. \\
\hline Ojos & & Superficiales. \\
\hline Brotes & & $\begin{array}{l}\text { Morado oscuro. } \\
\text { pubescentes. }\end{array}$ \\
\hline Nro. de tubérculos & & Alto. \\
\hline Periodo de latencia & & $\begin{array}{l}\text { Medio } \\
\text { (8-10 semanas) }\end{array}$ \\
\hline
\end{tabular}

- Calidad del tubérculo

Materia seca : $\quad 20 \%$.

Azúcares reductores : $\quad 0.05 \%$.

Calidad de hojuelas : Muybuena.

Color de hojuelas : : Muybueno.

Calidad de fritura : $\quad$ Muy bueno.

Color de fritura : : Muybueno.

Calidad culinaria : Buena.

- Resistencia a virus

Inmune a PVX

Inmune a PVY

Muy resistente a PLRV

\section{- Resistencia a nemátodos}

Buena resistencia de campo al nemátodo del nudo de la raíz (RKN), Meloidogyne incognita, M.javanica y M.arenaria.

\section{- Resistencia a hongos}

Resistencia moderada de campo a la rancha de la papa, Phytophthora infestans. Resistencia moderada de campo al tizón temprano, Alternaria solani.

\section{- Resistencia a estreses abióticos}

Salinidad

Sequía

Calor

Toxicidad por boro :

- Periodo vegetativo

Precoz ( 90-100 días).

\section{- Adaptación}

A la costa y sierra media semiárida. Tiene mejor rendimiento en primavera (27-30 t/há), en invierno, otoño y verano presenta rendimientos comerciales 
(20-25 t/há). Debido a su relativa insensibilidad al fotoperíodo y a las temperaturas estacionales presenta un amplio rango de adaptación a la costa peruana.

\section{- Época de siembra}

Por su tolerancia al calor y precocidad, puede ser sembrada y cultivada en las cuatro estaciones del año, lo cual permite satisfacer la demanda continua de material prima de la agroindustria de la papa.

\section{- Producción de la semilla prebásica}

Las plántulas in vitro o los tuberculillos libres de patógenos pueden ser solicitados al laboratorio de semilla e invernaderos del Centro Internacional de la Papa, Lima, o de la Universidad Nacional Jorge Basadre Grohmann, Tacna.

\section{VARIEDAD "DESÉRTICA"}

Código experimental : SDC 92.045,

$$
\text { CIP } 391346.1 .
$$

Pedigree

$$
\text { C89.479 x } 3875521.3 \text {. }
$$

El progenitor femenino C89.479 es un clon élite generado por el departamento de Genética ý Mejoramiento del CIP, proviene de una familia híbrida muy precoz, tolerante al calor y con gran resistencia a los virus PVX y PVY. El clon superior 387521.3, usado como progenitor masculino para generar este híbrido, es también un clon precoz mejorado en el CIP, tiene buen vigor y gran potencial de rendimiento. Estas carcterísticas principales de ambos progenitores fueron ensambladas para generar este híbrido superior SDC92.045, hoy variedad desértica, llamada así por su destacada adaptación a las condiciones desérticas de la costa peruana con potencial agrícola.

\section{- Caracteristicas de la planta}

$\begin{array}{lll}\text { Vigor } & : & \text { Mediano a alto. } \\ \text { Altura } & : & 50-60 \mathrm{~cm} . \\ \text { Tallo } & : & \begin{array}{l}4-6 \text { por planta. } \\ \text { Verde claras, con } \\ \text { foliolos medianos. }\end{array} \\ \text { Pubescencia } & : & \begin{array}{l}\text { Escasa. } \\ \text { Flores }\end{array} \\ \text { Baycas, floración } & : & \begin{array}{l}\text { moderada. } \\ \text { muy escasas o }\end{array} \\ \text { Fertilidad del polen } & : & \begin{array}{l}\text { Munguna. } \\ \text { Muja (5-10\%). }\end{array}\end{array}$

- Características del tubérculo

Estolones

Muy cortos, tuberización compacta.
Forma

Tamaño

Oval-redondeada. Mediano, a los 70 días tiene tamaño comercial.

Color de la piel : $\quad$ Crema.

Color de la pulpa : : $\quad$ Amarillo claro.

Ojos

Brotes

Nro. de tubérculos

Periodo de latencia

Superficiales.

Verde-crema.

Medio.

Corto (5-6 semanas)

- Calidad del tubérculo

Materia seca : 21.10.

Azúcares reductores : $\quad 0.05$.

Calidad de las hojuelas: Muy buena.

Color de hojuelas : : Muy bueno.

Calidad de fritura : $\quad$ Muy buena.

Color de fritura : Muy bueno.

Calidad culinaria : Buena.

- Resistencia a virus

Inmune a PVX

Inmune a PVY

Resistente a PLRV

\section{- Resistencia a nemátodos}

Buena resistencia de campo al nemátodo del nudo de la raíz (RKN), Meloidogyne incognita, M.javanicay M.arenaria.

\section{- Resistencia a hongos}

Resistencia moderada de campo al tizón temprano, Alternaria solani.

- Resistencia a estreses abióticos

Salinidad

Mediana-alta

Sequía

(4-7 mmhs).

(riego restringido).

Calor : Alta (Promedio

$\left.24-27^{\circ} \mathrm{C}\right)$

Toxicidad por boro : $\quad$ Media (4-7 ppm).

\section{- Periodo vegetativo}

Muy precoz (80-90 días).

\section{- Adaptación}

Presenta buena adaptación a las condiciones áridas y salinas con potencial agrícola de la costa. Tiene alta tolerancia al calor y relativa insensibilidad al fotoperiodo y a las temperaturas estacionales. Se adapta al cultivo en la sierra media semiárida, especialmente para la producción de semilla básica y certificada. 


\section{- Época de siembra}

Debido a su gran precocidad y resistencia a los estreses abióticos comunes de la costa, puede ser sembrada en cualquier época del año, sobre todo en la costa central y sur.

Produce óptimos rendimientos (20-25t/há) durante la primavera y el otoño. Se recomienda sembrarla a principios de setiembre y de abril en la costa. En la sierra media en octubre y enero se pueden obtener dos cosechas de semilla básica y certificada por año para su comercialización en la costa.

\section{- Producción de semilla prebásica}

Este clon ya ha sido introducido al sistema de cultivo in vitro para limpiarlo de virus. El proceso de generación de plántulas y tuberculillos libres de patógenos está actualmente en marcha.

\section{VARIEDAD "BASADRE"}

\section{Código experimental}

Fedigree

$$
\begin{aligned}
& \text { SDC } 89.612 . \\
& \text { MEX.32 x XY. } .
\end{aligned}
$$

El clon superior MEX.32 generado por el Programa Nacional de Papa de México y utilizado como progenitor femenino para generar este híbrido es de alto rendimiento y amplia resistencia de campo a la rancha de la papa Phytophthora infestans. El progenitor masculino XY.9 es un clon élite mejorado en el departamento de Genética y Mejoramiento del Centro Internacional de la Papa, proviene de una familia híbrida muy precoz, tolerante al calor y muy resistente a los virus PVX y PVY. Estas carcaterísticas principales de ambos progenitores fueron ensambladas para generar el híbrido superior SDC 89.612, hoy denominado variedad "basadre" en homenaje al 25 aniversario de la creación de la Universidad Nacional Jorge Basadre Grohmann de Tacna.

\section{- Características de la planta}

$\begin{array}{lll}\text { Vigor } & : & \text { Alto. } \\ \text { Altura } & : & 50-60 \mathrm{~cm} . \\ \text { Tallo } & : & \begin{array}{l}-6 \text { por planta. } \\ \text { Hojas }\end{array} \\ \text { Pubescencia } & : & \begin{array}{l}\text { Abundante. } \\ \text { foliolos muy anchos }\end{array} \\ \text { Flores } & : & \begin{array}{l}\text { Blancas, floración } \\ \text { escasa. }\end{array} \\ \text { Bayas } & : & \begin{array}{l}\text { Muy escasas o } \\ \text { ninguna. }\end{array} \\ \text { Fertilidad del polen } & : & \text { Alta }(80-90 \%) .\end{array}$

- Características del tubérculo

Estolones

Forma

Tamaño

Color de la piel

Color de la pulpa

Ojos

Brotes

Nro. de tubérculos

Periodo de latencia

- Calidad del tubérculo

Materia seca

Azúcar reductor

Calidad de hojuelas

Color de hojuelas

Calidad de fritura

Color de fritura

Calidad culinaria

- Resistencia a virus

PVX inmune.

PVY inmune.

PLRV moderada resistencia.

\section{- Resistencia a nemátodos}

Buena resistencia de campo al nemátodo del nudo de la raíz, Meloydogine incognita, M.javanica y M.arenaria.

\section{- Resistencia a hongos}

Resistencia moderada de campo a la rancha de la papa Phytophthora infestans.

Resistencia moderada de campo al tizón temprano Alternaria solani.

- Resistencia a estreses abióticos

Salinidad

Sequía

Calor

Toxicidad de boro

- Periodo vegetativo

Muy precoz (80-90 días).
Media-alta (5-7 mmhs).

Media-alta (riego restringido). Alta (Promedio 23-26 $\left.{ }^{\circ} \mathrm{C}\right)$. Media (4-7 ppm). 


\section{- Adaptación}

OOTFRÁ

Costa peruana y sierra media semiárida. Debido a su relativa insensibilidad al FOTOTEMPERAPERIODO se ađapta para su cultivo con buenos rendimientos durante las cuatro estaciones del año. Sin embargo, su máximo potencial de rendimiento se obtiene durante la primavera (25-30 tn/há) y en las cuatro estaciones los rendimientos fluctúan de 20-25 tn/há en un periodo de 80 a 90 días.

\section{- Época de siembra}

Su tolerancia al calor y gran precocidad permite la siembra de esta variedad en cualquier época del año. Sin embargo, para un óptimo rendimiento se recomienda sembrar a principios de setiembre y a principios de abril en la costa central y surperuana. En la sierra semiárida se recomienda sembrar, para la producción de semilla certificada, a principios de octubre y enero.

\section{- Producción de semilla prebásica}

Este clon fue introducido al sistema de cultivo in vitro para su limpieza de virus y producción de semilla de calidad libre de patógenos. Plántulas in vitro y tuberculillos libres de patógenos se encuentran disponibles en los laboratorios de cultivo in vitro e invernaderos del Centro Internacional de la Papa y de la Universidad Jorge Basadre Grohmann de Tacna. Las organizaciones agrícolas dedicadas a la producción de semilla básica y certificada, pueden solicitar este material de propagación a costo reducido a estas instituciones.

\section{GENERACIÓN DE SEMILLA DE CALIDAD LIBRE DE VIRUS PARA DISTRIBUCIÓN REGIONAL}

En vista de la creciente demanda de semilla de las variedades mejoradas de papa y camote desérticas, por parte de los agricultores y semilleristas de la costa sur peruana, se inicio un programa para la generación de la semilla de calidad libre de virus y otros patógenos a partir de cultivo in vitro de tejidos de papa. Diez clones elites de papa fueron introducidos al sistema de cultivo in vitro, procedidos por el tratamiento de termoterapia, cultivo de meristemos, micropropagación y pruebas serológicas de ELISA, para determinar el buen estado sanitario de los propágulos. Este procedimiento inicial se realizó en los laboratorios de biotecnología del Centro Internacional de la Papa.

Los clones fueron limpiados de virus, dando resul-
IINIRG

tados negativos en pruebas ELISA para los virus PVX, PVY, PLRV, APMV, PVS y APLV. Luego se entregó al presenteproyectodostubosquecontenianunaplántula invitro de cada variedad. Estematerial fue masalmente micropropagado en el laboratorio de biotecnologíasección papa, de la Universidad Nacional de Tacna. Las variedades inicialmente micropropagadas fueron Tacna, Costanera, Basadre, Primavera y Desértica para generar semilla prebásica de primera generación clonal. Las plántulas fueron multiplicadas bajo condiciones de invernadero y transplantadas a camas substratos de arena musgo humus de lombriz de tierra y cáscara de arroz para la producción de tuberculillos (minitubers) y posterior multiplicación en el campo para la distribución de semilla Actualmente, se ha obtenido un total de 3500 plántulas in vitro de estas variedades. El proceso continuará hasta lograr por lo menos unos 800 kilos de semilla básica de calidad, de cada variedad, para distribuir a los semillaristas del Cuzco, Tacna, Moquegua y Arequipa. El control de calidad de la semilla prebásica, generada en los laboratorios se hará sistemáticamente usando las pruebas serológicas de ELISA para la detección de por lo menos los seis virus más comunes que atacan el cultivo de la papa en la costa peruana (PLRV, PVX, PVY, PVS, APMV Y APLV).

Ultimamente se ha establecido el Comité de Productores de papas Industriales de la Irrigación Majes, Arequipa (COPPIMA), para la producción comercial, mayormente de las variedades Tacna, Costanera, Primavera y Desértica. El potencial agrícola de la Irrigación Majes 1500 m.s.n.m. es de cerca de 20,000 hectáreas y un clima adecuado para la producción sostenida de materia prima para la agroindustria durante todo el año. Este comité así como otros, requerirán cientos de toneladas de semilla certificada, que posiblemente sea generada en la sierra del Cuzco (INIA, ARARIWA, etc.). La Universidad Nacional de Tacna y tal vez otra Institución que compita procesarán en forma sostenida los tuberculillos libres de virus y otros patógenos a los grandes semillaristas de semilla básica y certificada de la sierra sur. La agroindustria ha mostrado mucho interés en comprar la producción de papa en Majes. De esta manera se establecerá el ciclo de producción de plántulas in vitro hasta el procesamiento industrial, para entrar en forma sostenida a este ciclo es necesario que la Universidad Nacional de Tacna invierta fondos en la construcción de nuevos invernaderos y en el equipamiento moderno del Laboratorio de Cultivo in vitro de papa. 
Después de dos años de ensayos técnicos y logísticos en la producción de semilla de calidad, la Universidad Nacional de Tacna ha creado el Centro de Producción de Semilla Pre-básica de Papas Industriales (CEPAIN). Su mandato principal es producir y comercializar semilla pre-básica libre de patógenos de las nuevas variedades mejoradas de papa de alta calidad industrial, muy precoces con tolerancia al calor y salinidad moderada. EI CEPAIN, ubicado en la zona agroecológica árida y salina del desierto de Atacama, Tacna, $500 \mathrm{msmm} ., 18^{\circ} \mathrm{LS}$, cuenta con un laboratorio de cultivo in vitro diseñado y construido bajo los standards establecidos por el IBPGR. El laboratorio con siete ambientes en dúplex tiene un potencial de producción de 20000 plántulas in vitro cada 60 días. Los dos invernaderos anexos al laboratorio tienen una área total de producción efectiva de 205 m2 con una capacidad de producción de 10600 tuberculillos cada 70 dias. No se ha detectado diferencias significativas en el rendimiento de tuberculillos por $\mathrm{m}^{2}$ entre las variedades. Sin embargo la capacidad de producción baja hasta un $40 \%$ durante la primavera tardía y el verano. Bajo éstas condiciones de alta temperatura y fotoperiodo largo las variedades comerciales tardias de invierno como Cica Tomasa y Perricholi no tuberizan. La agroindustria, los semilleristas y los agricultores organizados vienen catalizando la micropropagación masal y producción de tuberculillos de primera generación clonal de las variedades de calidad industrial Tacna, Costanera, Primavera, Desértica, Basadre y Campeona y de los clones élites últimamente seleccionados por la agroindustria SDC89.315 y SDC92.172

\section{PAPAS TRANSGENICAS PARA EL DESIERTO PERUANO}

Se ha aislado exitosamente el gen productor de toxina letal para insectos B.t. berlinerde la bacteria del suelo Bacillus thuringiensis en los laboratorios de biotecnología Plant Genetic Systems de Bélgica. La introducción de éste gen a los tejidos in vitro de la Vr. precoz, y de calidad industrial Costanera, vía Agrobacterium tumefaciens, en los laboratorios del Centro Internacional de la Papa, catalizó el interés de usar plantas transgénicas (TG) en lo cultivos comerciales de papa en el Perú y Bolivia. Hasta ahora los resultados dela evaluación de plantastransgénicas de la Vr. Costanera han sido muy promisorios. Estas plantas TG han mostrado consistente resistencia de campo a la Polilla de la Papa (PTM), Phthonrimaea operculella y a la Mosca Minadora (PLM), Liryormiza huidobrensis en los campos experimentales de la Universidad Nacional de Tacna. Asimismo, se han obtenido resultados similares en las evaluaciones de las plantas TG bajo condiciones de almacén con alta presión de población de la Polilla de la Papa.

Gracias al gran apoyo logístico y financiero de la Compañía Agroindustrial de Papa Lamb Weston se realizó una visita a las Instituciones de Investigación, y producción comercial y procesamiento Industrial de las variedades mejoradas de papa en los estados de Washington y Oregón. Las observaciones realizadas en los ambientes y facilidades de la Lamb Weston, Nature Mark, USDA-Prosser y de la Universidad de Washington nos llevan a opinar sobre el gran avance en el mejoramiento genético convencional de la papa. Las nuevas estrategias de mejoramiento combinadas con la transformación genética y el uso intensivo de la biotecnología vegetal no solo han acelerado el avance de selección, sino también la generación de variedades comerciales de papa de calidad industrial con genes específicos introducidos mediante ingeniería genética. A continuación se menciona algunos logros observados.

\section{a. En el Control de Plagas insectiles}

Las plantas transgénicas de papa Monsanto NewLeaf están protegidas por el B.t. gene contra el ataque del Gorgojo Colorado de la Papa. Asimismo los laboratorios Monsanto han desarrollado plantas transgénicas de Algodón, Tabaco y Maíz resistentes al ataque de los gusanos del follaje.

\section{b. En el control de enfermedades}

Es conocido que las enfermedades fungosas $y$ viróticas tienen efectos devastadores en el cultivo comercial de la papa. Para el control de los áfidos o pulgones que transmiten las enfermedades viróticas a la papa se realizan grandes aplicaciones de insecticidas que contaminan el medio ambiente. Gracias a la biotecnología se ha logrado generar plantas transgénicas de variedades comerciales de papa con resistencia a los virus más comunes de la papa como el PVX, PVY y PLRV.

La enfermedad fungosa de la Papa conocida como Rancha de la Papa (PLB) causada por el hongo Phytophthora infestans sigue destruyendo los cultivos de papa en los países industrializados y del Tercer 
Mundo generando grandes pérdidas en la cosecha y de cientos de millones de dólares al año. Los trabajos de transformación genética para la obtención de variedades comerciales resistentes a la Rancha de la Papa están muy avanzadas.

\section{c. En el control de malezas}

Las malezas no solamente compiten con las plantas cultivadas por nutrientes, agua, espacio y luz, sino también son portadoras de plagas y enfermedades que atacan a los cultivos de papa. Por otra parte los métodos de control usados son muy laboriosos y costosos. La introducción del gen tolerante a herbicidas Roundup Ready y la generación de plantas de papa TG resistentes a herbicidas como el Roundup hecha por los laboratorios Monsanto ofrece una gran alternativa práctica y económica en el control integrado de malezas en el cultivo comercial de la papa.

\section{d. En la calidad industrial}

Laintroducciónde genes inductores de alta materia seca en los tubérculos de las plantas transgénicas de variedades comerciales ha mejorado la calidad industrial para su intensiva utilización en la agroindustria de exportación de la papa semifrita congelada.

Este germoplasma noble de plantas transgénicas puede ser introducido a los países del tercer mundo para el control integrado de plagas y enfermedades. Sin embargo, muchas de éstas variedades TG están adaptadas a las condiciones de clima temperado del hemisferio norte. Es posible que a través de convenios de Cooperación Técnica Internacional y planes de investigación colaborativas de beneficios mutuos se pueda introducir esos genes sintéticos aislados de otros organismos a las principales variedades peruanas comerciales mejoradas de papa ya adaptadas a las condiciones edáficas y climáticas de la costa y de la sierra Peruana.

\section{CONCLUSIONES EHIPOTESIS PLANTEADAS}

El estrés de sal probablemente cause más daño a las plantas en términos de pérdidas económicas que otro factor de estrés abiótico. Una razón fundamental para ejecutar trabajos de mejoramiento genético de plantas para estrés ambiental, es que mucho de la expansión de los cultivos del Tercer Mundo en el futuro, serán en suelos marginales, no adecuados para una agricultura comercial intensa. Modificando o controlando el medio ambiente es otra alternativa para controlar la salinidad. La interrelación genética-medio ambiente puede ser optimizada a través de estudios de mejoramiento genético de la planta con prácticas culturales, tal como se puede mostrar en estos experimentos con clones tolerantes a salinidad bajo riego por exudación. En el sistema de riego tecnificado, ya sea por goteo o exudación, hay un ahorro extraordinario de agua, además, mantiene el cultivo bajo estrés moderado por el suministro permanente y suficiente de humedad. Por consiguiente, un manejo integrado de los suelos árido-salinos de potencial agrícola, engloba la utilización de un riego tecnificado que proporciona un gran ahorro de agua, y la incorporación de variedades mejoradas tolerantes a salinidad y sequía. Se calcula que en la próxima década, los agricultores expandirán su frontera agrícola hacia suelos marginales, cuando estas áreas sean el último recurso para la producción de alimentos en el Tercer Mundo, con una explosión demográfica creciente. Nosotros pensamos que la explotación del potencial de papa y el camote, desarrollando nuevas variedades adaptadas a estos suelos marginales, irá paralela a la ampliación de la frontera agrícola en el desierto de la costa peruana.

Hasta ahora los resultados de la evaluación de clones mejorados para tolerancia a suelos áridosalinos, ilustran el potencial que tiene el cultivo de la papa para adaptarse a suelos marginales desérticos, donde hay poca disponibilidad de agua de riego. Desde inicios de 1985 hasta el verano de 1998, se han evaluado, bajo condiciones árido-salinas y en diferentes fotoperiodos más de 45000 híbridos avanzados de papa. Como resultado de esta investigación, se han seleccionado 35 clones elites de papa, tolerantes a salinidad y sequía y de calidad industrial. Así mismo se han identificado cerca de 15 familias superiores TPS que muestran una tolerancia moderada a los estreses abióticos más comunes de las zonas áridas. Esta adaptación ha sido verificada en varios experimentos bajo condiciones de primavera, verano, otoño e invierno en la costa sur peruana. Estos genotipos y familias TPS promisorios sobreviven bajo condiciones de salinidad y riego restringido, mientras que otras sucumben a estos estreses.

La adaptación a estas condiciones edáficas, también implica la tolerancia a toxicidad de boro y otros estreses diferentes a la salinidad, tales como deficiencias en nitrógeno, fósforo y zinc, propios de 
los suelos desérticos del sur del Perú. De estos 35 clones elites, 10 han sido introducidos al sistema de cultivo in vitro para su limpieza de virus, micropropagación y distribución a los sectores productivos. Los clones elites y familias TPS tolerantes a salinidad y sequía han mostrado rendimientos de 20 a $25 \mathrm{~T} / \mathrm{ha}$, aún bajo condiciones de calor primavera y verano y en un ciclo vegetativo de 90 días, fluctuando la salinidad del suelo irrigado durante el crecimiento de la papa de 5 a $15 \mathrm{mmh} / \mathrm{cm}^{2}$ en los clones elites y de 4 a $7 \mathrm{mmh} / \mathrm{cm}^{2}$ en familias TPS. Asi mismo el germoplasma mejorado ha mostrado una ganancia genética en la resistencia de campo a las razas virulentas del sur del nemátodo del nudo de la raíz, (Meloidogyne). Este material genético mejorado de papa esta siendo cultivadas en áreas y estaciones climáticas no tradicionales donde la producción comercial de estos cultivos sería limitante, sin la previa tolerancia genética a la salinidad y otros estreses edáficos propios del desierto.

Otros caracteres agronómicos comunes de este germoplasma mejorado, son también su gran precocidad y rangos altos de materia seca que lo hacen promisorio para procesamiento industrial. Todos los clones mejorados de papa son tolerantes al calor, debido a que las evaluaciones y selecciones han sido realizadas bajo condiciones de primavera tardia y verano. Además, de estos atributos de adaptación, las variedades de papa desértica tienen excelente calidad industrial que lo hacen potenciales para la agroindustria mediante un suministro sostenido y todo el año de materia prima. En este sentido, la Universidad Nacional de Tacna y el Centro Internacional de la Papa, en forma conjunta, han liberado las mejores variedades superiores de camote y papa, adaptadas a esta zona agroecológica, común en la costa peruana. Durante los tres últimos años ha habido también una fuerte participación en el proyecto del Convenio ALA-93 de la Comunidad Económica Europea en Majes - Arequipa.

La creciente demanda mundial de alimentos significa que más cultivos deben realizarse en zonas marginales, lo cual conlleva a problemas de estrés abiótico. Los suelos marginales presentan serios problemas de salinidad, acidez, alcalinidad, deficiencia de minerales y toxicidad de elementos como el boro, aluminio y hierro. Mejorar las plantas para la tolerancia a estreses abióticos y con buenos caracteres agronómicos, son dos caminos para incrementar la producción agrícola. En este sentido, el caudal genético de la papa ofrece una valiosa heredabilidad variable para el mejoramiento de resistencia al estrés abiótico. Esta variabilidad ha empezado a ser explotada en las zonas árido-salinas del desierto sur peruano. Desde el inicio de este proyecto de la investigación colaborativa a principios de 1985, hasta hoy día, siempre hemos tenido en mente aplicar el principio universal técnico y moderno de que: "El principal objetivo de la investigación fitogenética es obtener beneficios económicos de la superioridad heredada o de una combinación favorable de genes".

Durante los tres años de investigación observaciones realizadas en experimentos de campo ocasionalmenteen invernaderos, conducenaplantear algunas hipótesis en el mejoramiento de papa para zonas árido-salinas, para su análisis futuro. Estas hipótesis se resumen en lo siguiente:

- Existe una correlación entre la resistencia a salinidad y la resistencia a sequía. Los clones avanzados, resistentes a salinidad, muestran también una marcada resistencia a sequía moderada o riego restringido.

- No existe correlación entre la resistencia a salinidad con la resistencia al nemátodo del nudo de la raíz, M.incógnita (RKN). Muchos clones promisorios y avanzados con resistencia a los estreses abióticos (salinidad, boro y sequía) han sido descartados por su susceptibilidad al ataque de RKN.

- Hay una tendencia de los clones precoces tole. rantes a estreses abióticos de presentar un vigor del follaje moderado y un mayor indice de cosecha en las zonas áridas y salinas.

- Hay diferentes respuestas fenotípicas al efecto del fotoperiodo en los clones mejorados de papa y en familias híbridas de semilla botánica, especialmente en la latitud de $18^{\circ}$ sur, bajo condiciones de Tacna.

Sin embargo hay una correlación baja entre la resistencia a estreses abióticos a nivel de plántula (genotipo o seedlings) y la resistencia a nivel de generaciones clonales.

- Existe variabilidad genética para la insensibilidad al fotoperiodo correlacionado con una producción comercial sostenida en el germoplasma mejorado de papa para zonas áridas. Se puede seleccionar clones o familias TPS para una producción comercial en las cuatro estaciones del año.

- Hay una correlación positiva muy baja entre el grado de vigor del follaje y el peso total del tubérculo, bajo condiciones de suelos áridos y salinos. 
- No hay correlación entre el grado de clorosis, quemaduras de bordes de hojas por efecto de la toxicidad del boro edáfico y la capacidad de producción de tubérculos.

- No hay correlación entre la resistencia a salinidad y la resistencia a toxicidad de boro. Parece que ambas resistencias están controladas por la acción de diferentes grupos de genes.

- Los estreses abióticos en zonas árido-salinas afectan la calidad culinaria en los tubérculos de papa, sobre todo la acumulación de glicoalcaloides (solanina). Es necesario seleccionar clones "resistentes" a esta acumulación, la cual se ha detectado con mayor frecuencia en clones con tubérculos de pulpa amarilla.

\section{REFERENCIAS BIBLIOGRÁFICAS}

BUSO, J.A. (1990). Os programas de melhoramento genético de batata no Brasil. Proc.INTA-PROCIPA pp 31-34

CHAVEZ, R.; UPADHYA, M.; CABELLO R. BERRIOS, R.; SILES P. (1996). Producción de papa en zonas áridas y salinas a partir de semilla botánica. Factibilidad y Perspectivas. Rev.Ciencia y Desarrollo Vol. III 1996.

CHAVEZ R.; MENDOZA H.; ESPINOZA, J. (1995). Breeding sweet potato for adaptation to arid and saline soils. CIP, circular 1995, pp.2-6.

CHAVEZR., H. MENDOZA; J.ESPINOZA, J.FLOREZ; J.CHAVEZ; P.SILES, M.HUACOLLO (1994). Ampliando la base genética para resistencia a salinidad y sequia en el germoplasma mejorado de papa y camote. Rev. Nueva Imagen N'IV, pp13-27-A.

CHÁVEZ R., UPADHYA, M., MENDOZA, H., ESPINOZA, J., CABELLO, R. SILES, P., BOLLO, G., MELENDEZ, T., EYZAGUIRRE, J., MAQUERA C., MONASTERIO, K., (1996). Nuevas hipótesis y avances de selección en el mejoramiento genético de papa y camote para adaptación a suelos áridos y salinos. Rev. Ciencia y Tecnología. Vol. I, No 4.

EKANAYAKE, I.J. (1994). Estudios sobre el estrés por sequia y necesidades de riego de la papa. Guia de investigación CIP 30.

JATALA,P.(1978). Studies of the interretionships of the plantparasitic nematodes and other organismos on potatoes 2nd Nematode P.C. International Potato Center. Lima Perú pp 191-193
- El estrés moderado de sequía en un estado avanzado del crecimiento de la planta de papa de clones precoces y tolerantes a estreses abióticos favorece el la calidad de los tubérculos destinados paraprocesamiento industrial (tanto en forma, tamaño, materia seca y calidad de fritura).

- No hay correlación entre la tolerancia al calor y la tolerancia a bajas temperaturas en el germoplasma mejorado de papa para zonas árido-salinas. Sin embargo existe una baja frecuencia de clones elites con ambos atributos de adaptación.

MENDOZA, H.; CHAVEZ, R.,ESPINOZA, J.; ARÉVALO N. Diaz L.Avances enelmejoramientodepapaparazonasárido-salinas. Congreso Latinoamericano de la Papa. Lima, Perú.1991.

PONNAMPERUNA.F:N:(1982)Mejoramientodeplantascultivadas paratoleranciaalestrésadáfico. EnPlantimprovementand. somatic cell genetics. Edit.Indra VAsil. Et al 1982.

RICK,C.(1982). El potencial del germoplasma exótico de tomate para elmejoramiento genético. En plant improvement and Somatic gefi genetics.Edit.Indra Vasil.Et al 1982.

THOMPSON, P.G., MENDOZA H.A. Y PLAISTED.L. (1983). Estimacióndeparámetrosgenéticos relacionadosalapropagación delapapaporsemillabotánicaenunapoblaciónindigena. American Potato Journal, pp 393-401.

UPADHYA, M.D. YTHAKUR K.C.(1990). Constraintsandstrategies fortruepotatoseed(TPS) production. Groupmeetingoncommercial adoption of TPStechnology-Problemsand prospecvts. NewDelhi, Aug. 17-18 1990.

UPADHYA, M.D., KADIAN, M.S., THAKUR, K.C., KHATANA, V.S. (1990). Potential of true potato seed (TPS) for potato production in different agroclimatic zones of India.EARP abstracts. 11th Triennal Conference of the European Association for Potato Research, Edinburgh, Scotland, Jul 8-13,1990, pp 532-533. 
Ciencia \& Desarrollo 6

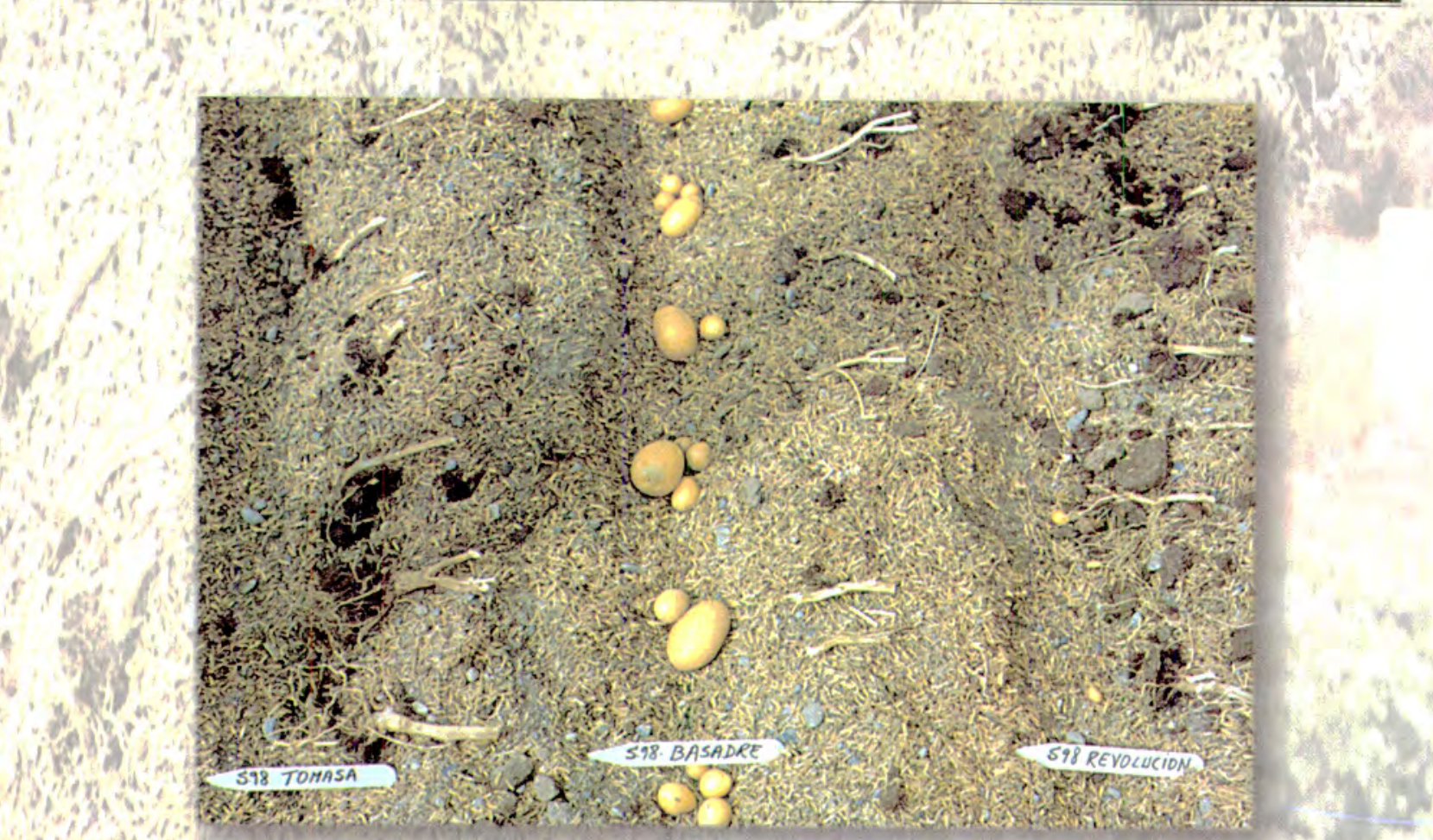

Foto 1. Póracción de los genes de tolerancia al calor la variedad Basadre tuberiza bajo condicionès de alta temperatura de verano (30$40^{\circ} \mathrm{C}$ ). Las yariedades susceptibles al calor como Tomasa y Revolución forman follaje vigoroso pero no tuberizan.

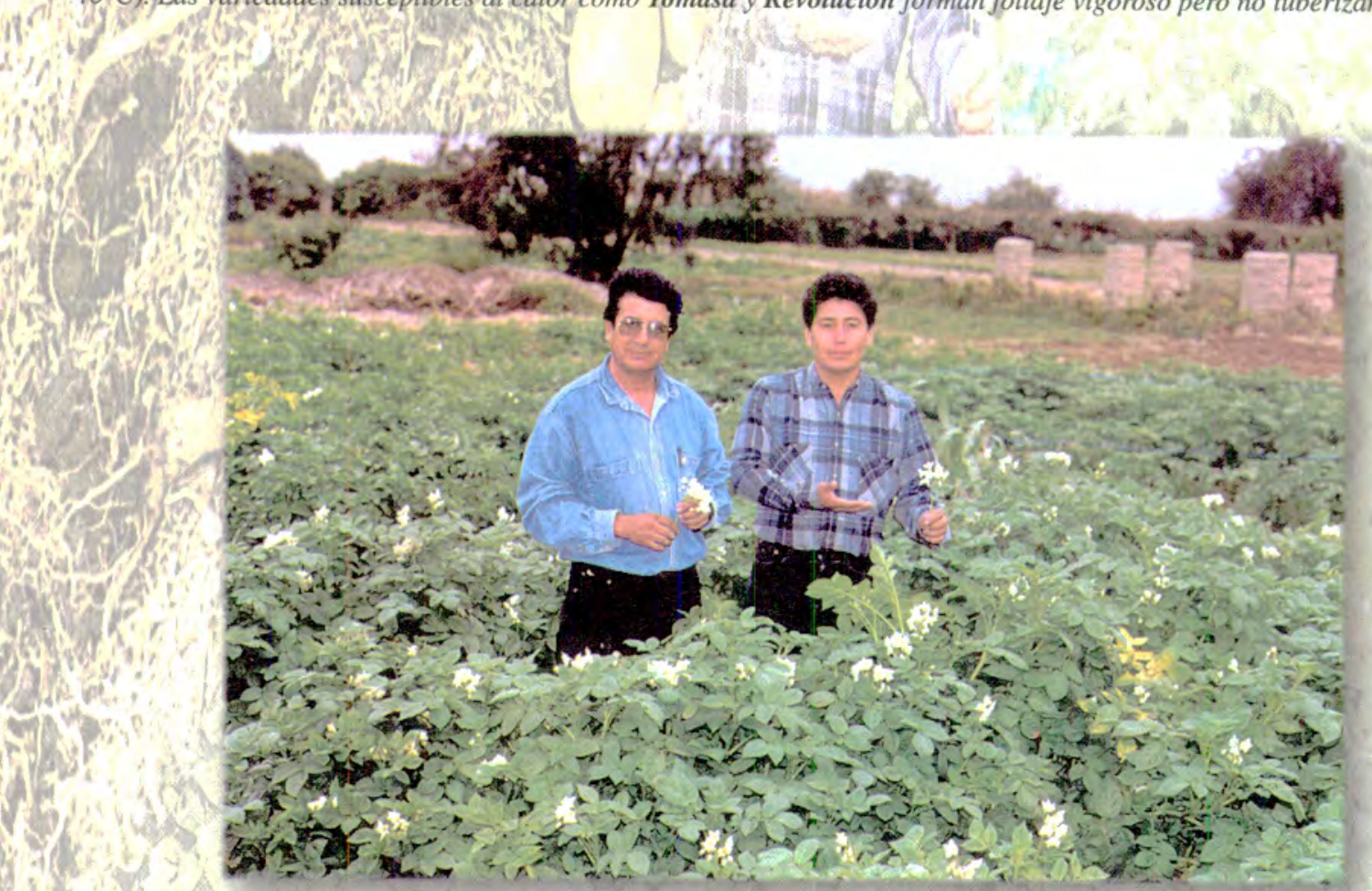

Foto 2. Cultivo experimental con plantas transgénicăs de la Vr. Costanera en zonas arido-salinas de Tacna. La marcada resistencia de campo a la Polilla y Mosca Minadora de la Papa se debe a la acción del gen B.t.ssp. Berliner aislado de la bacteria del suela Bacillus thuringiensis. Al centro, Rene A: Chấvez, lider del proyecto y su discipulos Luis Ayca. 


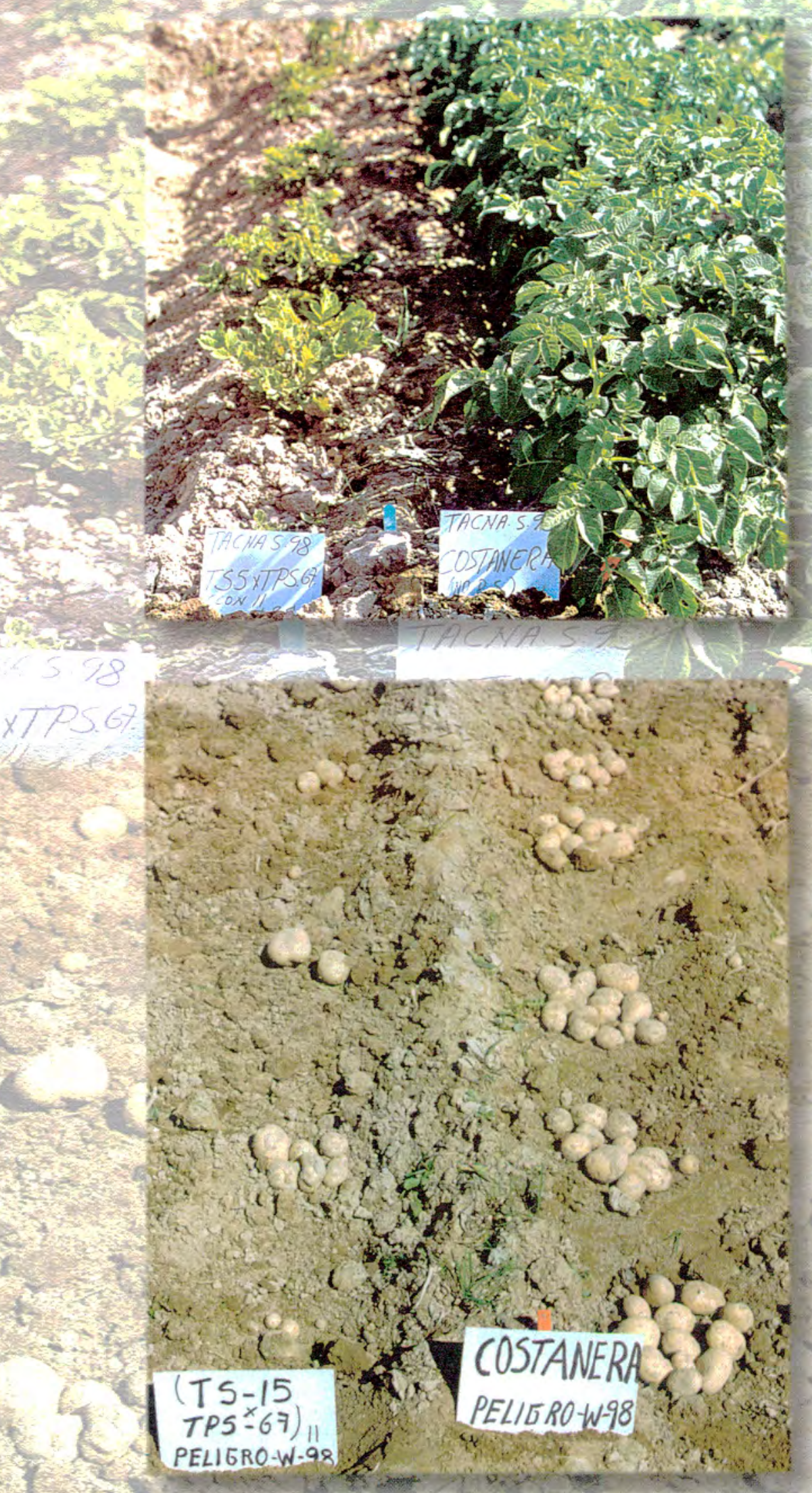

Foto 3. Dramática reducción del vigor y área foliar y producción de fubérculos por efecto del virus de enanismo rugoso en el clon avanzado (TS-15 x TPS-67). La semilla tuberculo utilizada fue de plantas previamente atacadas por la Cigarrita Ploma, Russelliana sotanicola, Las plantas vigorosas de la Vr. Costanera provienen de semuilla básica libre de virus. 
Cuadro 1 : Variedades mejoradas de papa en el Perú desarrolladas y liberadas entre 1957 y $1997(2 n=4 x=48=A A A A)$.

Fuente : R. Chávez ( 1997 Et al) Proyecto de Mejoramiento Genético y Adaptación de Papa y Camote en las Zonas Aridas y Salinas del Perí, Convenio: UNTAC - CIP - ALA 97.

Code : PO-14-97-UNTAC-CIP-ALA.

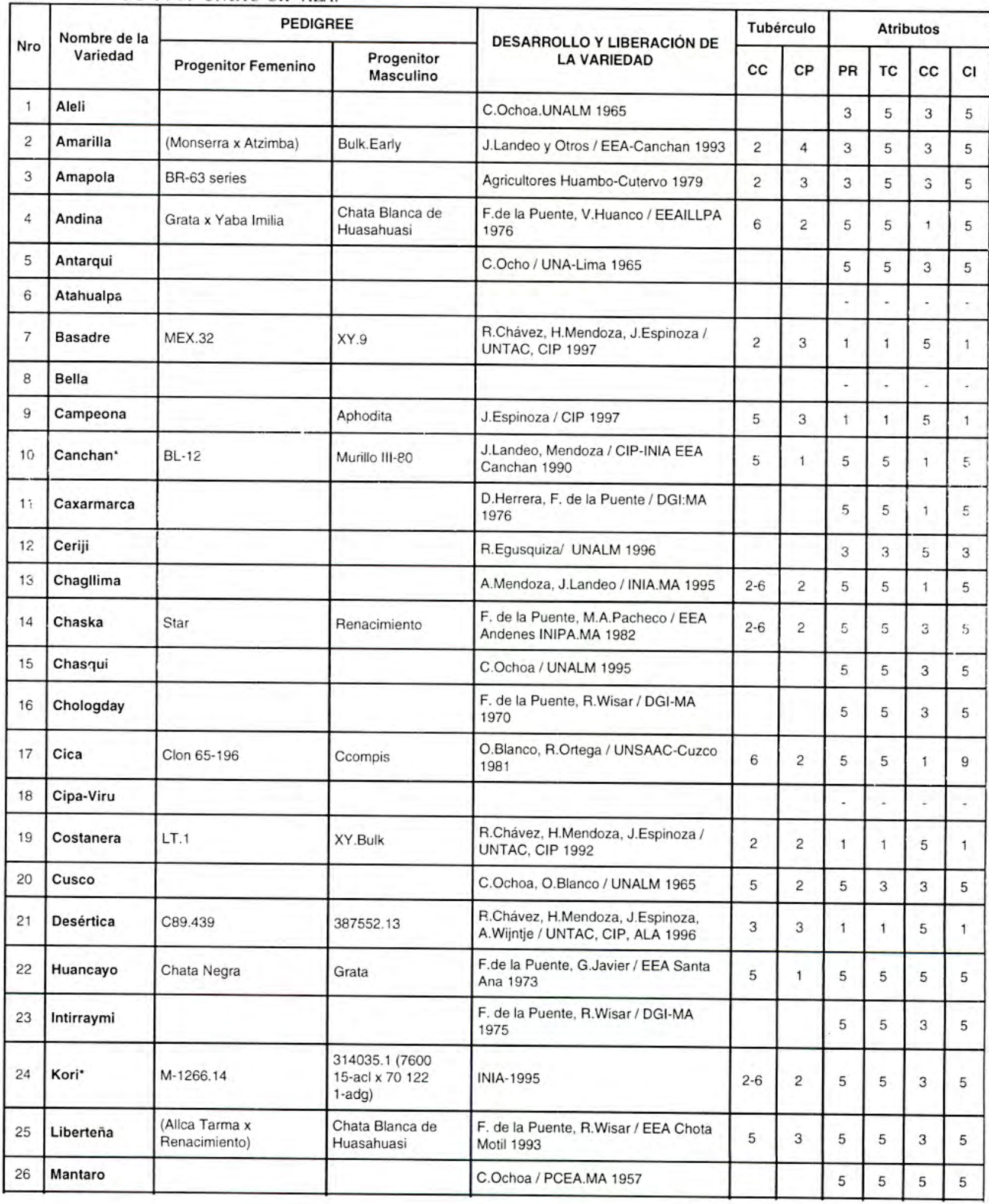




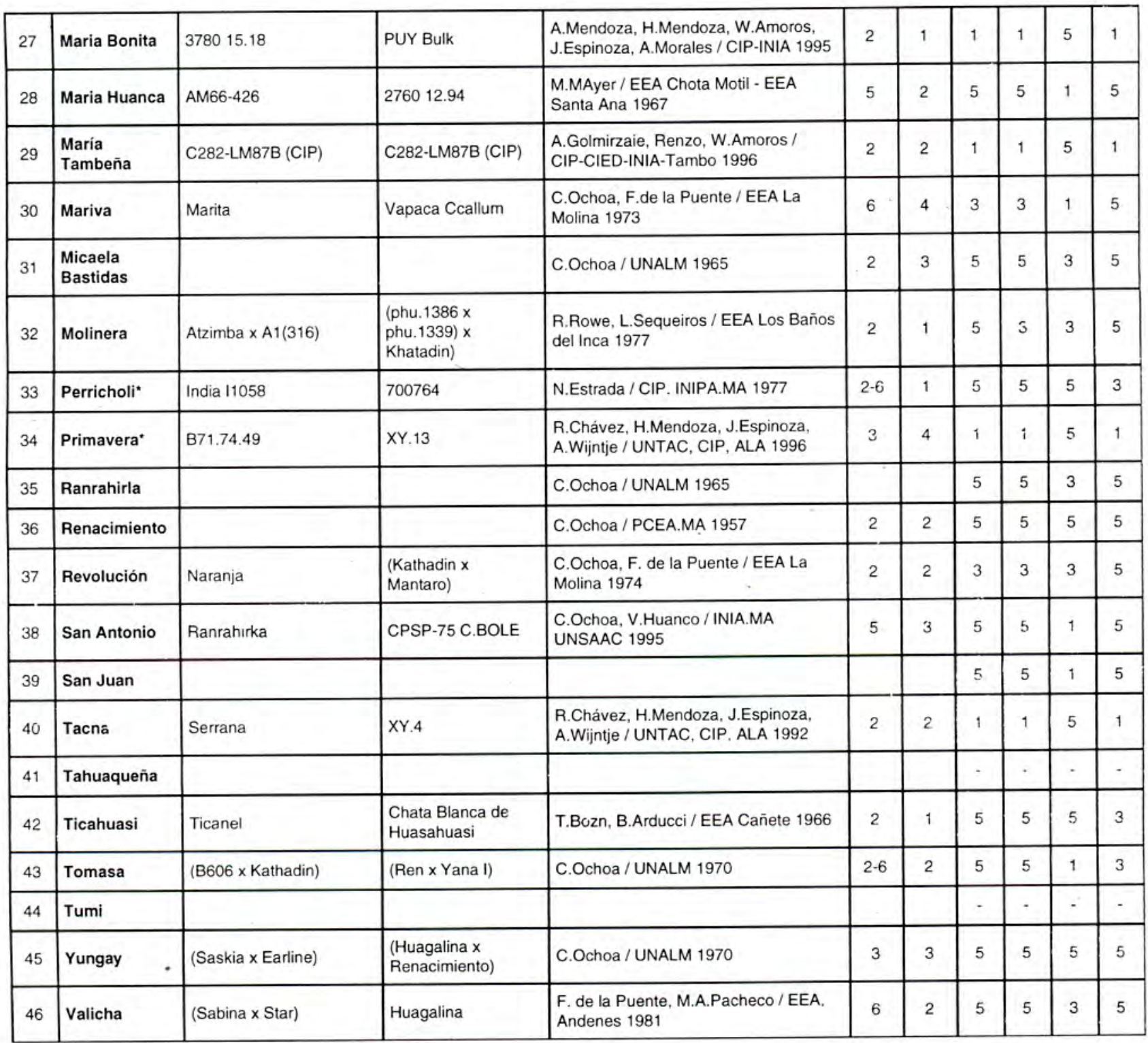

\section{DESCRIPTORES:}

- CC: Color de la cáscara

$1=$ blanco
$2=$ crema
$3=$ amarillo claro
$4=$ amarillo oscuro
$5=$ rojo
$6=$ púrpura

- CP: Color de la pulpa

1 = blanco

$2=$ crema

3 = amarillo claro

4 = amarillo oscuro

\section{ATRIBUTOS:}

\section{- PR: Precocidad}

$$
\begin{aligned}
& I=\text { precoz } \\
& 3=\text { semiprecoz } \\
& 5=\text { tardio }
\end{aligned}
$$

- CC: Calidad culinaria

$1=$ muy buena
$3=$ buena
$5=$ regular

- TC:Tolerancia al calor

$1=$ Tolerante

$2=$ medianamente tolerante

$5=$ susceptible

- CI: Calidad Industrial

$l$ = Muy buena

$3=$ Regular

$5=$ No apta 